\title{
Investigation on the Nonlinear Strength Properties and Damage Statistical Constitutive Model for Frozen Sandy Soils
}

\author{
De Zhang, ${ }^{1,2}$ Enlong Liu (D, , ${ }^{1,3}$ Xingyan Liu, ${ }^{1,2}$ Ge Zhang, ${ }^{1,2}$ Xiao Yin, ${ }^{3}$ and Bingtang Song ${ }^{1,2}$ \\ ${ }^{1}$ Northwest Institute of Eco-Environment and Resources, State Key Laboratory of Frozen Soil Engineering, \\ Chinese Academy of Sciences, Lanzhou, Gansu 730000, China \\ ${ }^{2}$ University of Chinese Academy of Sciences, Beijing 100049, China \\ ${ }^{3}$ State Key Laboratory of Hydraulics and Natural River Engineering, College of Water Resource and Hydropower, \\ Sichuan University, Chengdu, Sichuan 610065, China \\ Correspondence should be addressed to Enlong Liu; liuenlong@lzb.ac.cn
}

Received 11 September 2017; Accepted 27 November 2017; Published 11 March 2018

Academic Editor: Andres Sotelo

Copyright (c) 2018 De Zhang et al. This is an open access article distributed under the Creative Commons Attribution License, which permits unrestricted use, distribution, and reproduction in any medium, provided the original work is properly cited.

There are many flaws, such as fissures, cavities, and inclusions, in geomaterials, which make their mechanical properties with great randomness and uncertainty. Upon loading, the soil structure gradually losses the bearing capacity due to the transformation from microdefects to macroscopic breakage bands. Based upon the experimental data of frozen sandy soils, a new nonlinear strength equation between the first and third principal stresses was proposed, and then the nonlinear strength properties for frozen sandy soils in $\sigma-\tau$ plane were analyzed. In addition, by assuming that the microstrength of frozen sandy soil obeys the Weibull distribution function, a statistical damage constitutive model was established based upon the framework of continuum damage mechanics $(\mathrm{CDM})$, with few parameters and a high accuracy. Compared with experimental data, the new model can well grasp the nonlinear strength properties and simulate the stress-strain relationships under different confining pressures for frozen sandy soils.

\section{Introduction}

Frozen soils are geotechnical materials, which are mainly formed in cryogenic environment. Frozen soils are defined as those containing some ice and having a temperature at or lower than $0^{\circ} \mathrm{C}$ [1]. It is distributed all around the world regularly, such as Russia, America, China, and Canada, which accounts for $24 \%$ of the world's land area [2]. As far as the components are concerned, frozen soils are composite materials consisting of mineral particles, ice inclusions, liquid water, and gaseous inclusions [3], which are sensitive to temperature, loading rate, external load, soil types, water content, confining pressure, etc. The typical problems in cold regions can be mainly summarized as the frost-heaving effect, thawing-settlement effect, and freeze-thaw cycle effect in these regions. It is well known that the frost-heaving effect causes the structure damage due to the extension of microcracks. Simultaneously, the thawing-settlement effect induces irreversible plastic deformation. Terribly, the interactions of the two effects aggravate the damage and destruction of structures. Hence, up to present, many researchers have studied the physical and mechanical characteristics of permafrost and seasonal frozen soils, such as nonlinear strength properties and damage deformation behaviors.

Currently, a great number of research achievements have been obtained on this field for unfrozen soils and frozen soils. For instance, the mechanical properties of unfrozen soils are obtained with great progress. Matsuoka and Nakai [4] considered the stress deformation and strength characteristics of soil under three different principal stresses. Liu et al. $[5,6]$ proposed a general strength criterion for geomaterials, considering isotropic and anisotropic effects. Meanwhile, Liu et al. [7] employed a nonlinear DruckerPrager and Matsuoka-Nakai unified failure criterion for geomaterials to describe the nonlinear strength properties with separated stress invariants. Yao et al. $[8,9]$ established a general nonlinear strength theory, which was extensively employed in concrete, rock, sand, clay, etc. Moreover, Yao et al. $[10,11]$ proposed a unified strength criterion (USC) for 
geomaterials to describe the triangle curved shape, which was the combination of SMP criterion and extended Mises criterion in the deviatoric plane, and then he defined a linear interpolation function between the two criteria to describe the shape function. The nonlinear strength envelope mentioned above can be described by hyperbolic, parabolic, exponential, power functions, etc. For structured soils, Liu et al. [12] proposed a new strength criterion based on binarymedium constitutive model (BMCM), and its expressions on both meridian and deviator planes are given. Due to the peculiar and complicated properties of frozen soils, most of the strength criteria are not completely suitable and should be modified for further applications based upon experimental results. Fish [13] and Ma et al. [14] gave a parabolic function to describe the strength properties. Qi and Ma [15] modified the classical Mohr-Coulomb strength criterion to apply for frozen sandy soils considering the influence of confining pressures. Lai et al. [16] established a parabolic curve for frozen silt soils in the meridian plane and Lade-Duncan model in the deviatoric plane to describe the shape function. Lai et al. [17] and Liao et al. [18] modified the hydrostatic pressure to simulate the strength in the $q$ - $p$ plane and employed a combination of LD and SMP models to describe the deviatoric plane. Lai et al. [19] proposed a relationship between the first principal $\sigma_{1}$ and the third principal stress $\sigma_{3}$, and then they established a nonlinear strength formula for frozen sandy soils. The researches mentioned above mainly concentrate on the nonlinear properties of unfrozen soils and frozen soils. The classical and modified strength criterion cannot completely reflect the nonlinear characteristics for frozen soils, so it is necessary to establish an appropriate strength criterion to describe the nonlinear properties of frozen soils.

At the same time, many research results of the stressstrain curves were obtained, especially in rock damage mechanism, mechanical properties, and strength and deformation characteristics [20-29]. On the theoretical framework of continuum damage mechanics (CDM), probability, and statistics theory, the damage constitutive models were established and could well simulate the stressstrain process for geological materials. For instance, Ren et al. [30] studied microdamage mechanism and damage constitutive model on the basis of uniaxial compression tests and found that the damage mechanism could appropriately describe the variation of stress-strain relationship. Later, a series of experimental study on rock were conducted by Zhang et al. [31] to analyze the weakened mechanism and damage properties under the freezing-thawing conditions. Ren [32] carried out computed tomography (CT) tests to study breakage mechanism for frozen cracked rock from a mesoscopic point of view. Lai et al. [33] and Li et al. [34] proposed a new and an improved statistical damage constitutive model for warm frozen clay and warm ice-rich frozen clay based upon the experimental results and applied Mohr-Coulomb criterion to judge whether the frozen soil element is damaged or not. Xu et al. [35] made an investigation on strength and deformation characteristics of ice-saturated frozen sandy soil and then proposed a nonlinear strength criterion and simultaneously employed an improved Duncan-Chang model to simulate the deformation properties. The researches mentioned above are the latest research achievements.

Due to the peculiar and complicated characteristics of frozen soils, some strength criteria, such as Mohr-Coulomb, Drucker-Prager, and Hoek-Brown strength criterion, are not suitable for frozen soils. So, the classical strength criterion should be modified or a new strength criterion may be established to investigate the nonlinear strength properties and breakage mechanism for frozen soils. Therefore, in this paper, a relationship between the first and third principal stresses is proposed, and then the nonlinear strength properties of frozen sandy soils are investigated. Furthermore, a new statistical damage constitutive model is also proposed, and the model parameters are determined by cryogenic triaxial compression tests data. Finally, the applicability of the new constitutive model is validated by comparisons between predicted and experimental data.

\section{Test Result Analysis}

As is illustrated in Figure 1 from Lai et al. [17], it can be found that the stress-strain curves go through the linear stage under relatively small axial strain to the elastoplastic stage. In addition, the curves present strain-softening phenomenon under low confining pressures and strain-hardening phenomenon under relatively high confining pressures. From the volumetric strain-axial strain curves, it is indicated that the volume of specimen is compressed at first and then dilated under low confining pressures, while it is merely compressed under high confining pressures. The determination method of peak values of stress-strain curves can be obtained as follows: (a) when the stress-strain curves present strain softening, the maximum value of $\sigma_{1}-\sigma_{3}$ is taken as the strength of frozen soil in this paper and (b) when the stress-strain curves present strain hardening, the value of $\sigma_{1}-\sigma_{3}$ at axial strain $\varepsilon_{a}=20 \%$ is taken as the strength of frozen soil [33]. The relationship between deviatoric stress $q$ and mean stress $p$ is depicted in Figure 2, which indicates that the strength increases first and then decreases with increasing mean stress $p$.

\section{Nonlinear Strength Theory of Frozen Sandy Soils}

\subsection{Existing Classical Strength Criterion}

3.1.1. Mohr-Coulomb Strength Criterion. In geomaterial engineering, the Mohr-Coulomb criterion is widely used to predict the strength and deformation properties; hence, one of the classical strength criteria can be described as follows:

$$
\sigma_{1}-\sigma_{3} \tan ^{2}\left(45^{\circ}+\frac{\varphi}{2}\right)-2 c \tan \left(45^{\circ}+\frac{\varphi}{2}\right)=0,
$$

where $c$ and $\varphi$ denote the cohesive force and internal frictional angle, respectively. In this paper, for the test data, $c=4.332$ and $\varphi=0.3792$.

3.1.2. Hoek-Brown Nonlinear Criterion. In the early years, Hoek [36] proposed the Hoek-Brown criterion based upon 


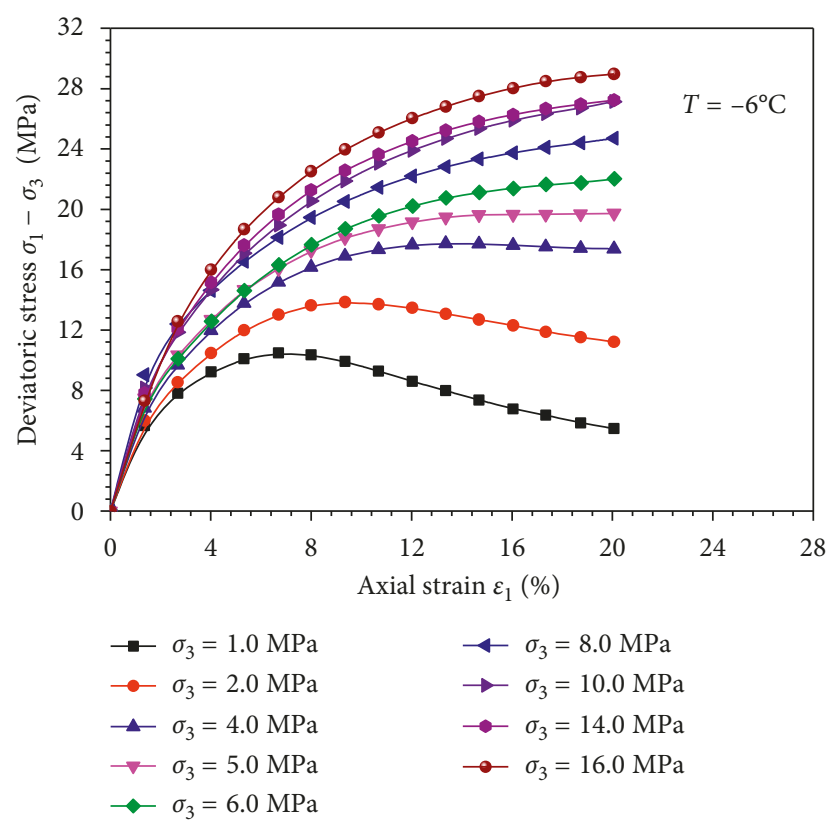

(a)

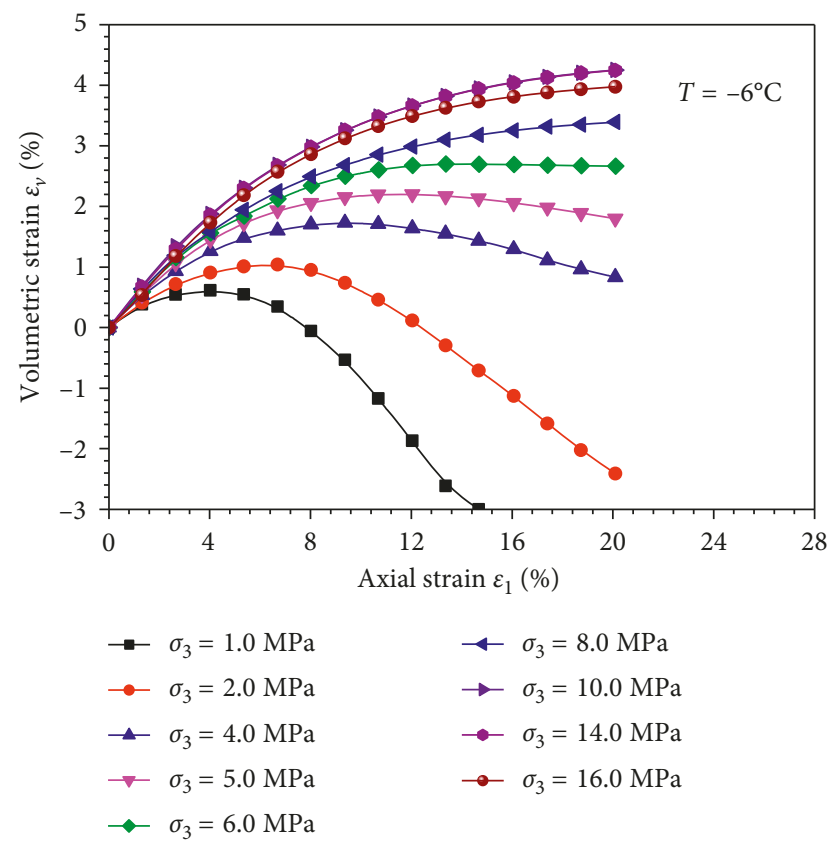

(b)

FIgURE 1: The curves of deviatoric stress-axial strain (a) and volumetric strain (b) of frozen sandy soils (Lai et al. [17]).

hundreds of experimental results and numerous field test findings for rock materials. It is an empirical strength criterion, and the expression can be presented in the following form:

$$
\sigma_{1}-\sigma_{3}-\sqrt{m \sigma_{3} \sigma_{c}+s \sigma_{c}^{2}}=0
$$

where $\sigma_{c}, m$, and $s$ are material parameters. In this paper, for the test data, $\sigma_{c}=3.63, m=15.17$, and $s=6.782$.

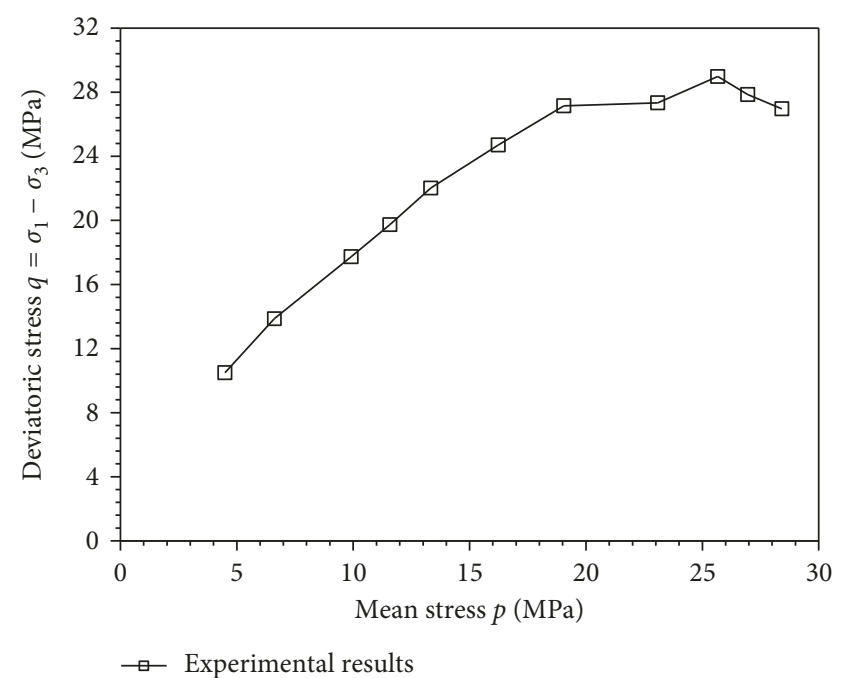

Figure 2: The strength envelope in the meridian plane.

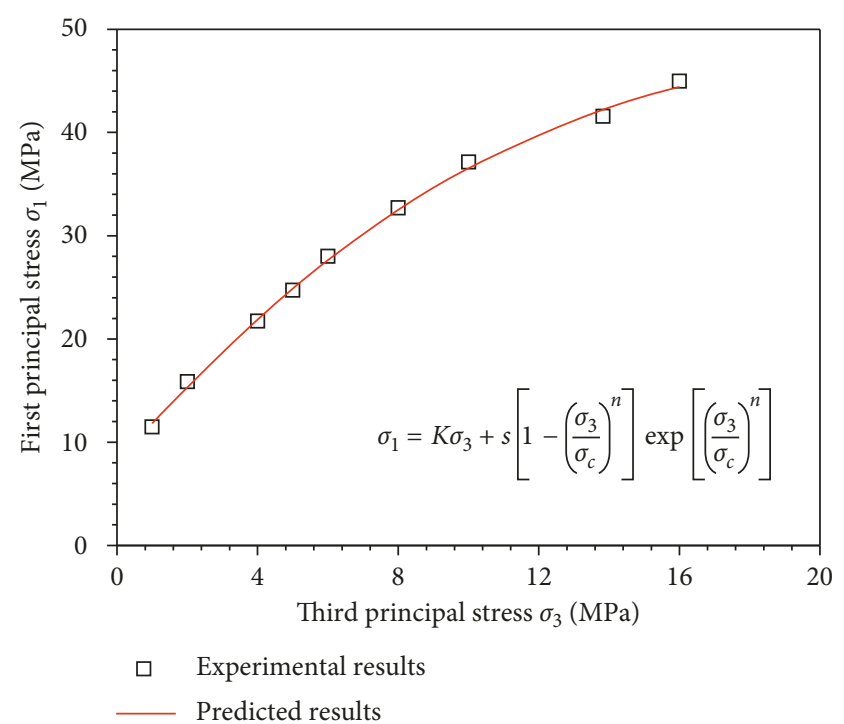

FIGURE 3: The relationship between the first principal stress and the third principal stress of frozen sandy soils.

3.2. The Evolution of the Proposed Strength Criterion. Based upon the experimental data from Figure 1, we can obtain the relationship between $\sigma_{1}$ and $\sigma_{3}$, as illustrated in Figure 3. In order to investigate the nonlinear strength characteristics, we propose an empirical equation as follows:

$$
\sigma_{1}=K \sigma_{3}+s\left[1-\left(\frac{\sigma_{3}}{\sigma_{c}}\right)^{n}\right] \exp \left[\left(\frac{\sigma_{3}}{\sigma_{c}}\right)^{n}\right],
$$

where $K, s, n$, and $\sigma_{c}$ are material parameters, respectively, which can be determined based on experimental results. In this paper, for frozen sandy soils, $K=6.449, s=8.252$, $\sigma_{c}=2.82$, and $n=0.394$ and the fitting coefficient $R^{2}=0.997$.

For convenience, in the $\sigma$ - $\tau$ plane, (3) can be rewritten as

$$
f=\sigma_{1}-K \sigma_{3}-s\left[1-\left(\frac{\sigma_{3}}{\sigma_{c}}\right)^{n}\right] \exp \left[\left(\frac{\sigma_{3}}{\sigma_{c}}\right)^{n}\right] \text {. }
$$




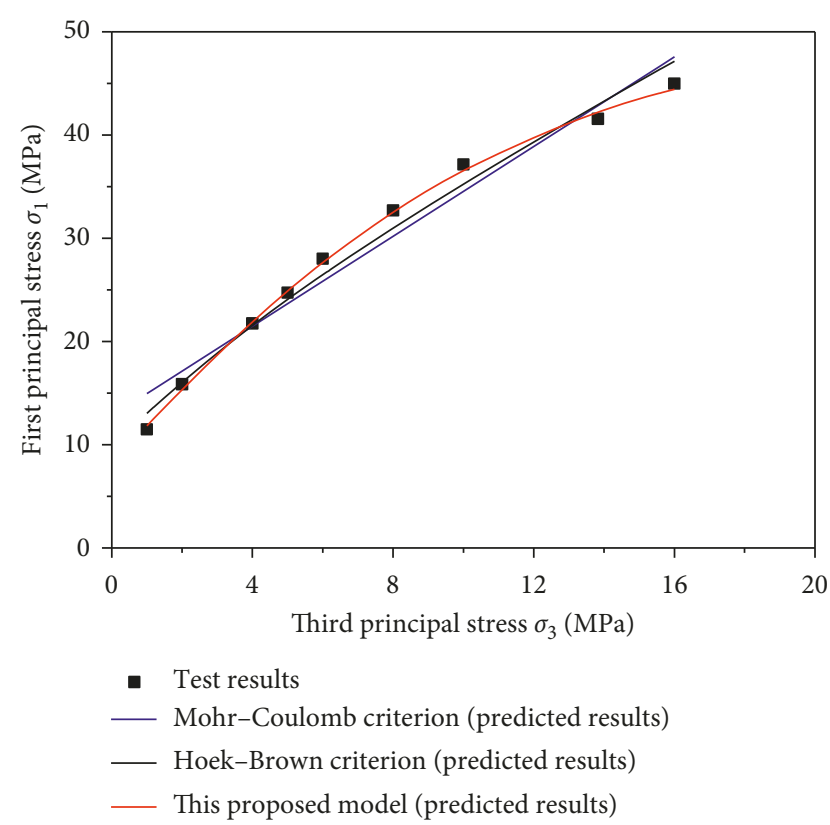

FIgURE 4: Comparisons between predicted results and experimental data.

According to experimental results, compared with the classical strength criteria, such as Mohr-Coulomb strength criterion and Hoek-Brown nonlinear criterion, the proposed nonlinear strength results are more close to the experimental data, as is depicted in Figure 4. It demonstrates that the new strength criterion can simulate the experimental results of frozen sandy soils well.

3.3. Nonlinear Strength Theory of Frozen Sandy Soils. Figure 5 shows the graphical illustration of the relationship between stress state $A(\sigma, \tau)$ and failure envelop $f$. That is, when the stress state $A(\sigma, \tau)$ is at the top of Mohr's circle, the failure envelope is represented by $\tau=f(\sigma)$. It should be noted that the failure loci presents a nonlinear changing tendency, which is also called a failure state line. The experimental maximum stress in the failure envelope is tangent to Mohr's circle, which is the intersection point of $A(\sigma, \tau)$. From Figure 5, it is known that the failure stress state is represented by the point $A$, which cannot transcend the failure loci $\tau=f(\sigma)$. The mathematical relationship of Mohr's circle can be described as

$$
g\left(\sigma_{1}, \sigma_{3}\right)=\left(\sigma-\frac{\sigma_{1}+\sigma_{3}}{2}\right)^{2}+\tau^{2}-\left(\frac{\sigma_{1}-\sigma_{3}}{2}\right)^{2}=0
$$

By differentiating (4) and (5), we can obtain the following equations:

$$
\begin{aligned}
& d f\left(\sigma_{1}, \sigma_{3}\right)=\frac{\partial f}{\partial \sigma_{1}} d \sigma_{1}+\frac{\partial f}{\partial \sigma_{3}} d \sigma_{3}=0, \\
& d g\left(\sigma_{1}, \sigma_{3}\right)=\frac{\partial g}{\partial \sigma_{1}} d \sigma_{1}+\frac{\partial g}{\partial \sigma_{3}} d \sigma_{3}=0 .
\end{aligned}
$$

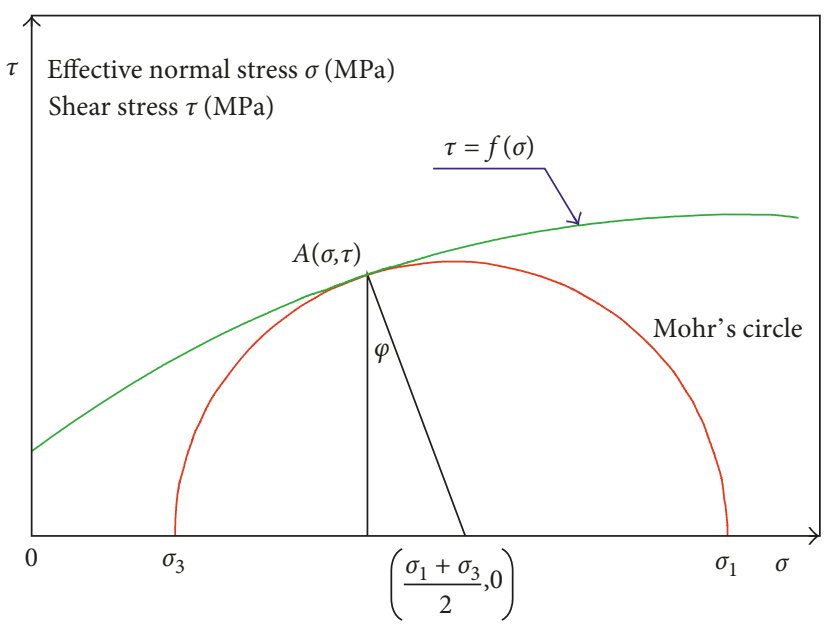

Figure 5: Schematic description of Mohr's circle.

Due to the independence of $\sigma_{1}$ and $\sigma_{3}$, the relationship of $d \sigma_{1} / d \sigma_{3}$ can be calculated as

$$
\frac{d \sigma_{1}}{d \sigma_{3}}=\frac{\partial \sigma_{1}}{\partial \sigma_{3}}=-\frac{\partial g / \partial \sigma_{3}}{\partial g / \partial \sigma_{1}}=-\frac{\partial f / \partial \sigma_{3}}{\partial f / \partial \sigma_{1}} .
$$

Based on the framework of the envelope theorem by Lai et al. [19], for simplification, (8) can be rewritten as

$$
\frac{\partial f}{\partial \sigma_{1}} \cdot \frac{\partial g}{\partial \sigma_{3}}-\frac{\partial f}{\partial \sigma_{3}} \cdot \frac{\partial g}{\partial \sigma_{1}}=0
$$

Differentiating (4) for $\sigma_{1}$ and $\sigma_{3}$, respectively, we can obtain the following:

$$
\begin{aligned}
& \frac{\partial f}{\partial \sigma_{1}}=1+\frac{\partial \sigma_{3}}{\partial \sigma_{1}}\left\{\frac{s n}{\sigma_{3}}\left(\frac{\sigma_{3}}{\sigma_{c}}\right)^{2 n} \exp \left[\left(\frac{\sigma_{3}}{\sigma_{c}}\right)^{n}\right]-K\right\}, \\
& \frac{\partial f}{\partial \sigma_{3}}=\frac{\partial \sigma_{1}}{\partial \sigma_{3}}-K+\frac{s n}{\sigma_{3}}\left(\frac{\sigma_{3}}{\sigma_{c}}\right)^{2 n} \exp \left[\left(\frac{\sigma_{3}}{\sigma_{c}}\right)^{n}\right], \\
& \frac{\partial g}{\partial \sigma_{1}}=-\sigma+\sigma_{3}+\frac{\partial \sigma_{3}}{\partial \sigma_{1}}\left(\sigma_{1}-\sigma\right), \\
& \frac{\partial g}{\partial \sigma_{3}}=-\sigma+\sigma_{1}-\frac{\partial \sigma_{1}}{\partial \sigma_{3}}\left(\sigma-\sigma_{3}\right) .
\end{aligned}
$$

Substituting (12) and (13) into (8), the normal stress is expressed as

$$
\sigma=\sigma_{3}+\frac{\sigma_{1}-\sigma_{3}}{1+\left(\partial \sigma_{1} / \partial \sigma_{3}\right)}
$$

Substituting (14) into (5), the shear stress is expressed as

$$
\tau=\frac{\sigma_{1}-\sigma_{3}}{1+\left(\partial \sigma_{1} / \partial \sigma_{3}\right)} \sqrt{\frac{\partial \sigma_{1}}{\partial \sigma_{3}}} .
$$

Furthermore, we can easily get the expression of internal frictional angle based upon the triangle relationship shown in Figure 5 as follows: 


$$
\tan \varphi=\frac{\left(\left(\sigma_{1}-\sigma_{3}\right) / 2\right)-\sigma}{\tau} .
$$

Substituting (14) and (15) into (16), we can obtain the following:

$$
\varphi=\tan ^{-1}\left[\frac{\left(\partial \sigma_{1} / \partial \sigma_{3}\right)-1}{2 \sqrt{\partial \sigma_{1} / \partial \sigma_{3}}}\right]
$$

Differentiating (4) for $\sigma_{3}$, the result is presented as follows:

$$
\frac{\partial \sigma_{1}}{\partial \sigma_{3}}=K-\frac{s n}{\sigma_{3}}\left(\frac{\sigma_{3}}{\sigma_{c}}\right)^{2 n} \exp \left[\left(\frac{\sigma_{3}}{\sigma_{c}}\right)^{n}\right] .
$$

Finally, substituting (18) into (14), (15), and (16), in the $\sigma-\tau$ plane, the expressions of normal stress $\sigma$, shear stress $\tau$, and internal frictional angle $\varphi$ of the nonlinear strength criterion can be rewritten as

$$
\begin{aligned}
\sigma= & \frac{K \sigma_{3}-\operatorname{sn}\left(\sigma_{3} / \sigma_{c}\right)^{2 n} \exp \left[\left(\sigma_{3} / \sigma_{c}\right)^{n}\right]+\sigma_{1}}{K+1-s n / \sigma_{3}\left(\sigma_{3} / \sigma_{c}\right)^{2 n} \exp \left[\left(\sigma_{3} / \sigma_{c}\right)^{n}\right]}, \\
\tau= & \frac{\sigma_{1}-\sigma_{3}}{K+1-s n / \sigma_{3}\left(\sigma_{3} / \sigma_{c}\right)^{2 n} \exp \left[\left(\sigma_{3} / \sigma_{c}\right)^{n}\right]} \\
& \times \sqrt{K-\frac{s n}{\sigma_{3}}\left(\frac{\sigma_{3}}{\sigma_{c}}\right)^{2 n} \exp \left[\left(\frac{\sigma_{3}}{\sigma_{c}}\right)^{n}\right]}, \\
\varphi= & \tan ^{-1}\left\{\frac{K-1-s n / \sigma_{3}\left(\sigma_{3} / \sigma_{c}\right)^{2 n} \exp \left[\left(\sigma_{3} / \sigma_{c}\right)^{n}\right]}{2 \sqrt{K-s n / \sigma_{3}\left(\sigma_{3} / \sigma_{c}\right)^{2 n} \exp \left[\left(\sigma_{3} / \sigma_{c}\right)^{n}\right]}}\right\},
\end{aligned}
$$

where the expressions of (19) and (20) can be known as failure envelope in the $\sigma-\tau$ plane for frozen sandy soils.

3.4. Verification. Based upon experimental data, the nonlinear strength envelope can be obtained from (19) and (20), as is illustrated in Figure 6, in which the same parameters in Section 3.2 are used. The schematic diagram distinctively presents the nonlinear strength properties. Compared with experimental results, the proposed expression of (4) about $\sigma_{1}$ and $\sigma_{3}$ can well grasp and simulate the nonlinear strength characteristics of frozen sandy soils. It can be found that the proposed relationship is closer to the experimental results than Mohr-Coulomb strength criterion or Hoek-Brown strength criterion. It is convinced that the proposed equation can appropriately reflect the nonlinear strength properties with the increase of confining pressures.

The influence of confining pressure on the internal frictional angle is investigated as well, as illustrated in http:// www.nrcresearchpress.com/doi/full/10.1139/javascript:void(0) (Figure 7). It can be found that the frictional angle decreases with increasing confining pressure due to pressure melting and crushing phenomenon. It should be noted that the internal frictional angle is negative when the confining pressure is nearly $14.0 \mathrm{MPa}$, which is coincident with the research results by $\mathrm{Ma}$ et al. [37]. It is indicated that the temperature of ice increases by $1{ }^{\circ} \mathrm{C}$ when the applied pressure increases by $13.5 \mathrm{MPa}$ in the theoretical study on the basis of the Clapeyron equation. And thus, the predicted results can appropriately account for the phenomenon of pressure melting and crushing.

\section{Damage Statistical Constitutive Model for Frozen Sandy Soils}

4.1. Formulation of the Damage Statistical Constitutive Model. Similar to unfrozen geomaterials, such as rock, concrete, rockfill material, sand, and clay, the damage process can be mainly accounted for by the same token. That is, the degradation of the material makes the effective areas decrease and the effective stress increase. Accordingly, the intact specimens are easy to damage due to the appearance of fissures, cracks, defects, and shear bands.

Based on the strain equivalent principle [38], the strain caused by apparent stress $\sigma_{i j}$ applied to a damaged material is equal to the strain caused by equivalent stress $\sigma_{i j}^{*}$ acting on the undamaged material. Hence, the tensor expression can be described as follows:

$$
\varepsilon_{i j}=M_{i j k l} \sigma_{k l}^{*}=M_{i j k l}^{*} \sigma_{k l}=\left(I_{i j k l}-D_{i j k l}\right) M_{k l m n} \sigma_{m n},
$$

where $M_{i j k l}^{*}$ and $M_{i j k l}$ denote the elastic flexibility matrix tensors of damaged material and undamaged material, respectively; $\sigma_{i j}^{*}$ and $\sigma_{i j}$ represent the equivalent stress matrix tensor and apparent stress matrix tensor, respectively; $\varepsilon_{i j}$ represents the strain matrix tensor, $I_{i j k l}$ is an identity matrix tensor, and $D_{i j k l}$ is a damage matrix tensor.

Based on phenomenological method, basic assumptions by Lai et al. $[33,39]$ are carried out for frozen soils. At first, on a macroscale, the soil specimen, regarded as a representative volume element (abbreviated as RVE), is isotropic and contains the basic information of damage, while it is a microheterogeneous material in the mesolevel. In addition, the linear elastic law is applied when the frozen soil element remains undamaged, and the nonlinearity of the stress-strain relationship is derived from the damage of the material. So, we can take the initial tangent modulus as the elastic modulus of the undamaged material. The damage variable is defined as the ratio of damaged section area to total section area in the mesolevel, and in macroscopic view, it is defined as the ratio of the number of damaged frozen soil elements to the number of all frozen soil elements. So, the damage expression defined is given as follows:

$$
D=\frac{N^{\text {damage }}}{N^{\text {total }}}
$$

where $N^{\text {damage }}$ denotes the number of damaged frozen soil elements and $N^{\text {total }}$ stands for the number of all frozen soil elements, respectively. 

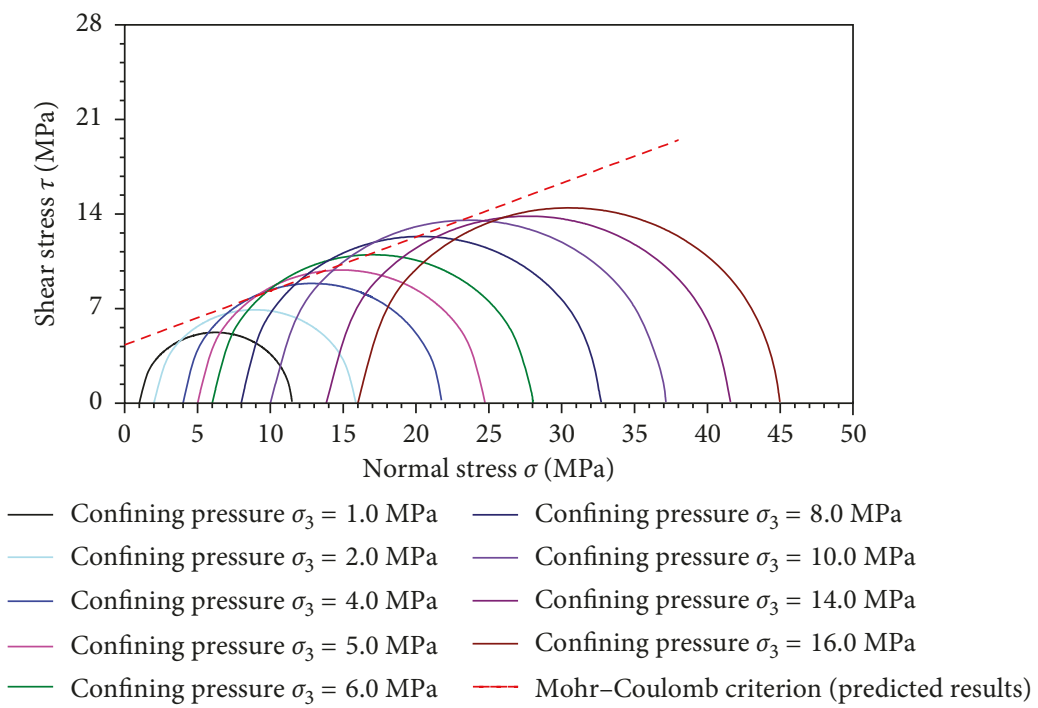

(a)
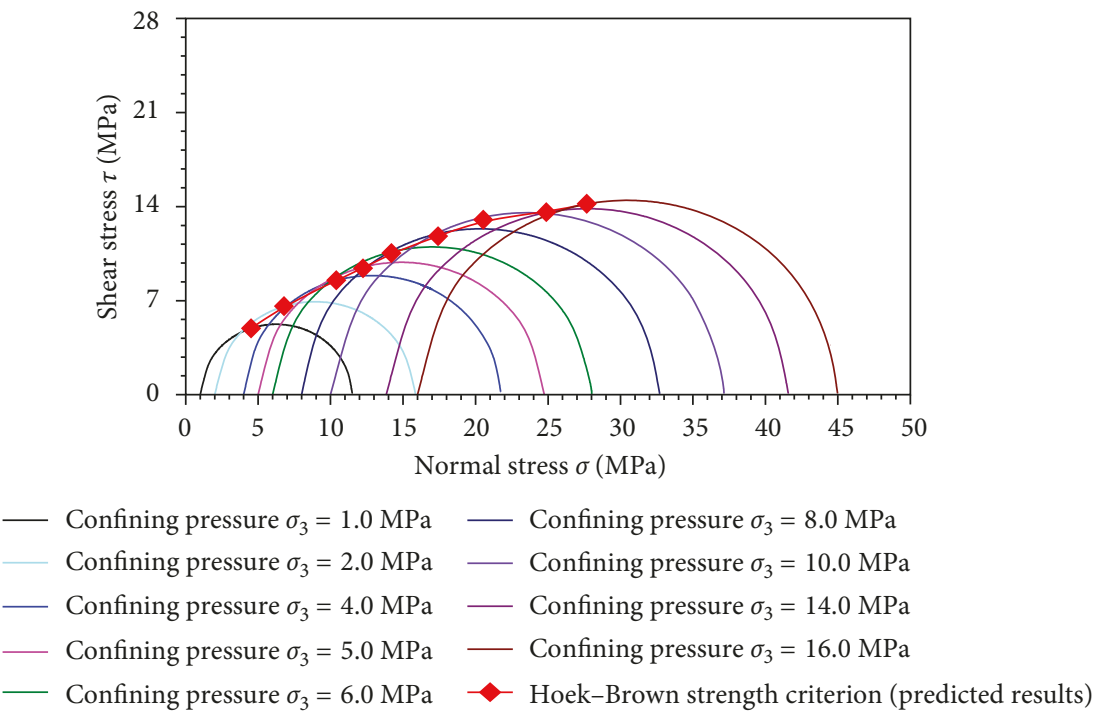

(b)

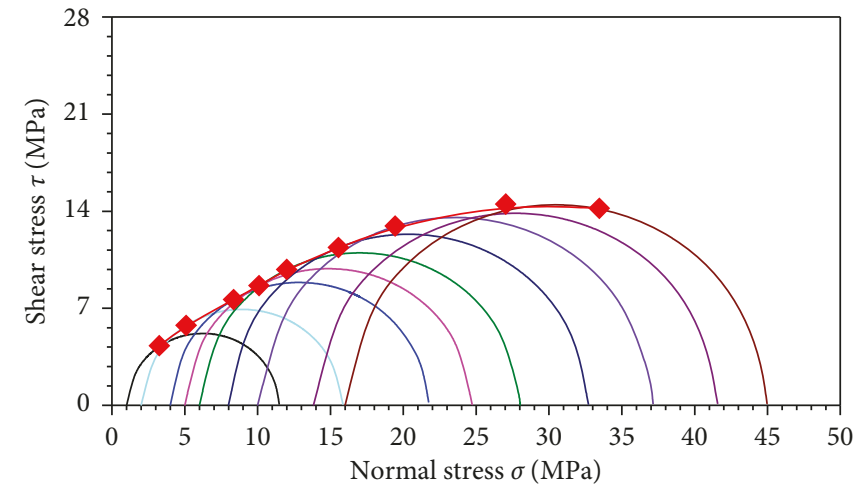

$\begin{aligned} \text { - Confining pressure } \sigma_{3}=1.0 \mathrm{MPa} & - \text { Confining pressure } \sigma_{3}=8.0 \mathrm{MPa} \\ \text { Confining pressure } \sigma_{3}=2.0 \mathrm{MPa} & - \text { Confining pressure } \sigma_{3}=10.0 \mathrm{MPa} \\ \text { Confining pressure } \sigma_{3}=4.0 \mathrm{MPa} & - \text { Confining pressure } \sigma_{3}=14.0 \mathrm{MPa} \\ \text { - } \text { Confining pressure } \sigma_{3}=5.0 \mathrm{MPa} & - \text { Confining pressure } \sigma_{3}=16.0 \mathrm{MPa} \\ \text { Confining pressure } \sigma_{3}=6.0 \mathrm{MPa} & - \text { The proposed model (predicted results) }\end{aligned}$

(c)

FIGURE 6: Nonlinear strength envelope for frozen sandy soils under various confining pressures. Comparisons between (a) Mohr-Coulomb strength criterion and experimental results, (b) Hoek-Brown strength criterion and experimental results, and (c) the proposed model and experimental results. 


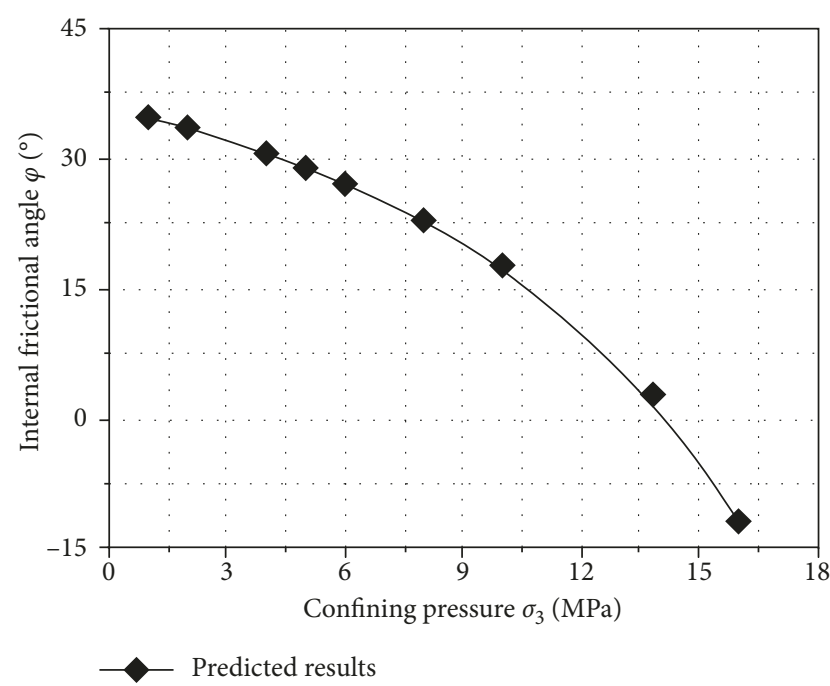

FIgURE 7: The evolution law of internal frictional angle.

4.2. Weibull Distribution Function. Compared with the other probability distribution function [40], it is found that the Weibull distribution can well describe the breakage process of rock [20-22] and warm frozen silt clay [33, 39]. In the paper, it is assumed that the microstrength of frozen sandy soil obeys the Weibull distribution as well. When the stress level reaches the value of $F$ as is illustrated in the later section, the internal flaws and fissures gradually increase and transform to macrocracks or shear bands. So, the expression of probability density for damaged frozen sandy soil elements can be obtained as follows:

$$
f(F)=\frac{m}{F_{0}}\left(\frac{F}{F_{0}}\right)^{m-1} \exp \left[-\left(\frac{F}{F_{0}}\right)^{m}\right],
$$

where $f(F)$ represents the probability density function of microstrength for frozen sandy soil, $F$ denotes the yield criterion, and $m$ and $F_{0}$ are material parameters of the Weibull distribution function.

The yield criterion for frozen sandy soils can be written as

$$
F\left(\sigma_{i j}^{*}\right)=k_{i} \text {, }
$$

where $k_{i}$ denotes the failure strength, which varies with internal state parameters, such as stress level, stress history, stress path, cohesive force, and internal frictional angle.

By integrating the microstrength function of (24), we can get the number of damaged frozen sandy soil elements as follows:

$$
N^{\text {damage }}=\int_{0}^{F} N^{\text {total }} f(x) d x .
$$

Substituting (24) and (26) into (23), the damage variable $D$ can be obtained as follows:

$$
D=1-\exp \left[-\left(\frac{F}{F_{0}}\right)^{m}\right]
$$

From (25) and (27), it can be found that the independent variable $F$ changes with the varying stress state.

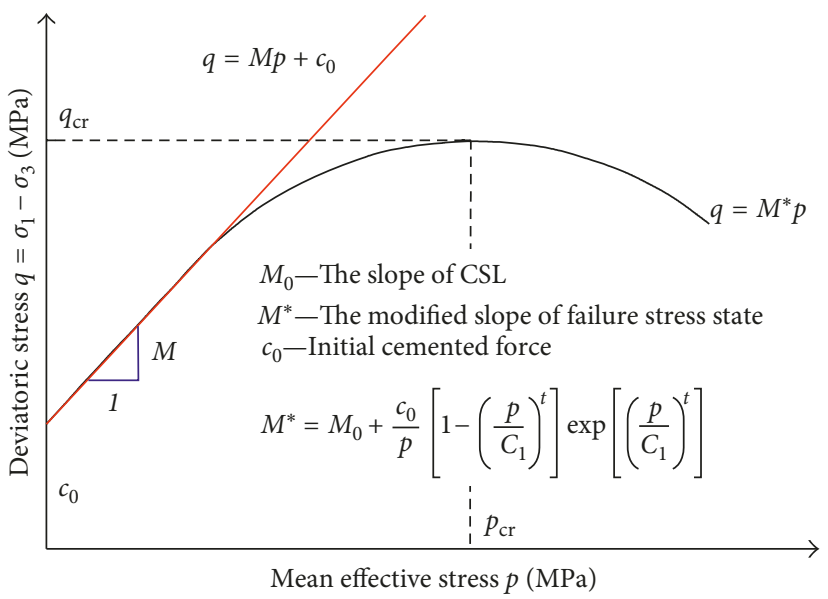

FIGURE 8: Relationships of stress-strain curves for frozen soils in the meridian plane.

4.3. A New Strength Criterion for Frozen Sandy Soil. Based upon the framework of critical state soil mechanics [41], for unfrozen soils as noncohesive materials, the strength envelope is a straight line and is passing through the original point of the coordinates in the meridian plane. With respect to frozen soils, the bonding effect of ice crystals and soil particles possesses tensile strength, which will be weakened due to the pressure melting under relatively high confining pressures, similar to the cohesive behaviors of cemented clay. In the previous study $[13,14,17,18,37]$, it is indicated that the strength of frozen soils increases first and then decreases with the increase of confining pressures. The maximum value $q_{\max }$ of the $q-p$ curve corresponds to failure mean stress $p_{\mathrm{cr}}$. When the stress $p$ is lower than $p_{\mathrm{cr}}$, the $q-p$ curve can be replaced by linear strength criterion in the meridian plane, such as Mohr-Coulomb criterion and Druck-Prager criterion. While the stress $p$ is higher than $p_{\mathrm{cr}}$, the $q$ - $p$ curve starts to bend downward due to pressure melting. In order to simulate evolution laws of the failure state for frozen sandy soils of the phenomenon, Fish [13], Ma et al. [14, 37], and Lai et al. [16] suggested a parabolic formula for frozen soils in the meridian plane, and Lai et al. [16] meanwhile proposed the Lade-Duncan model to simulate the strength characteristics in the deviatoric plane. Later, Nguyen et al. [42] proposed that the CSL of the cemented clay eventually reduced to an asymptote coinciding with the CSL of natural clay. Lai et al. [17] and Liao et al. [18] employed a modified mean effective stress expression to describe the strength criterion for frozen soils.

Hence, in this paper, based on the research results of Nguyen et al. [42], Lai et al. [17], and Liao et al. [18], we propose a modified strength criterion to simulate the variation tendency of the first increasing and then decreasing phenomena for frozen sandy soils. Here, the graphic illustration and the proposed modified strength criterion are given in Figure 8 and (28) to (30).

From Figure 8 , the modified failure state line can be written as follows: 
TABLE 1: Basic physical parameters determined.

\begin{tabular}{lcc}
\hline $\begin{array}{l}\text { Confining pressures, } \\
\sigma_{3}(\mathrm{MPa})\end{array}$ & $\begin{array}{c}\text { Bulk modulus, } \\
\text { K }(\mathrm{MPa})\end{array}$ & $\begin{array}{c}\text { Shear modulus, } \\
G(\mathrm{MPa})\end{array}$ \\
\hline 1.0 & 505.1 & 440.2 \\
2.0 & 1133.1 & 514.9 \\
4.0 & 2104.7 & 642.2 \\
5.0 & 2531.1 & 694.7 \\
6.0 & 3244.2 & 739.7 \\
8.0 & 4116.2 & 807.6 \\
10.0 & 4898.1 & 845.9 \\
14.0 & 5329.2 & 833.4 \\
16.0 & 5455.5 & 782.7 \\
\hline
\end{tabular}

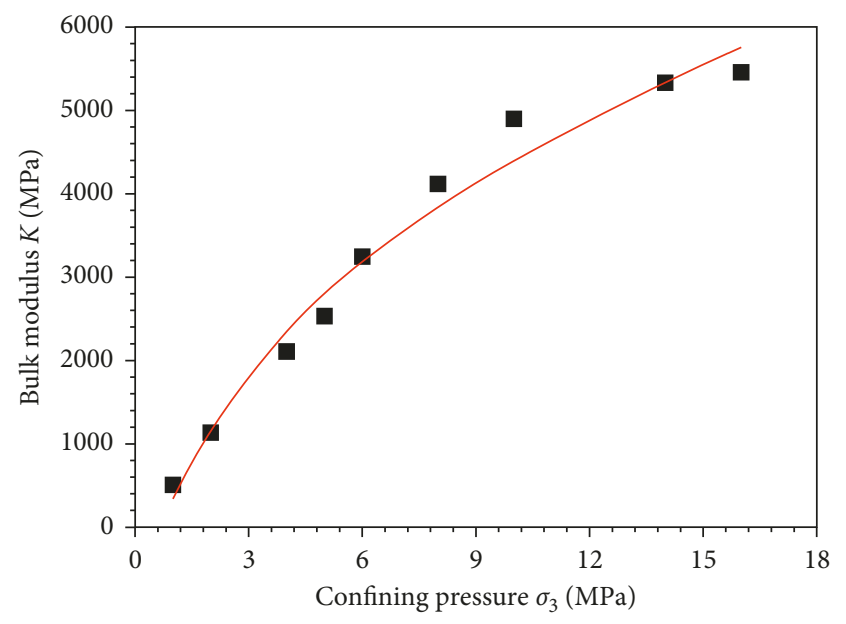

- Experimental results - Predicted results

(a)

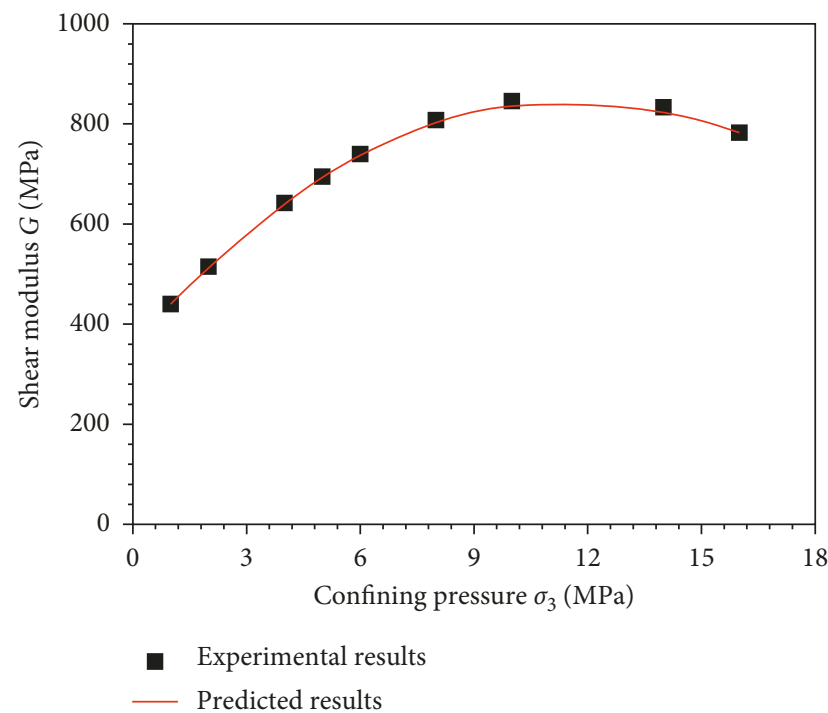

(b)

Figure 9: The predicted results of the bulk modulus $K(\mathrm{a})$ and shear modulus $G$ (b) with experimental data.
TABLE 2: Parameter determination of the strength criterion.

\begin{tabular}{|c|c|c|c|c|}
\hline \multicolumn{5}{|c|}{ Parameter values of frozen sandy soil } \\
\hline$M_{0}$ & $c_{0}$ & $C_{1}$ & $t$ & \\
\hline 1.503 & 1.494 & 16.68 & 0.9479 & 0.9971 \\
\hline
\end{tabular}

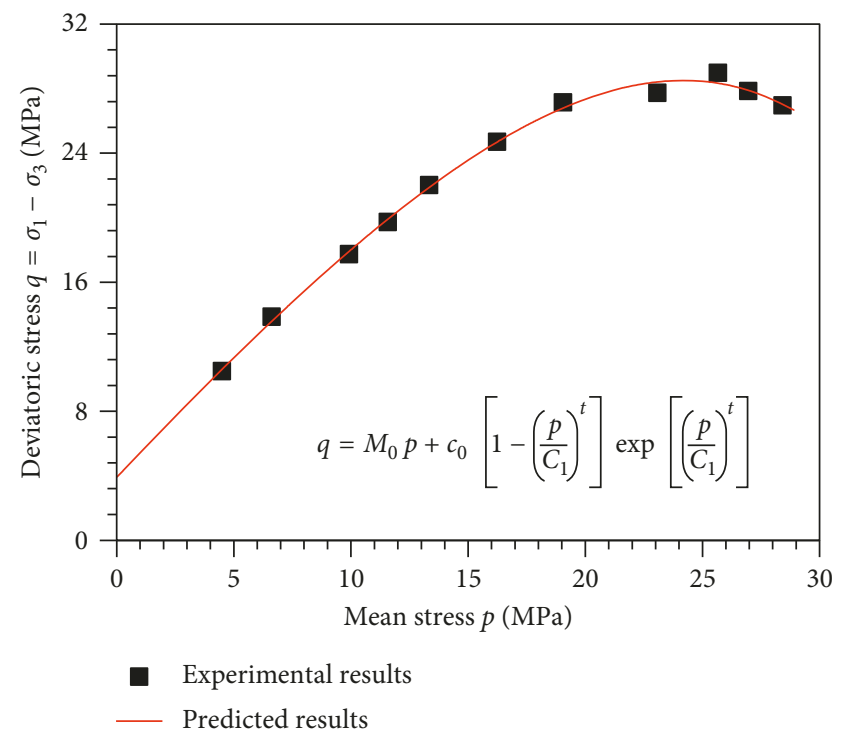

Figure 10: Comparisons between experimental data and predicted results under different confining pressures.

TABle 3: Parameter determination of the damage constitutive model of (46).

\begin{tabular}{lcc}
\hline Confining pressures, & \multicolumn{2}{c}{ Parameter determination } \\
$\sigma_{3}(\mathrm{MPa})$ & $1.1948 E-01$ & $F_{0}$ \\
\hline 1.0 & $7.3400 E-02$ & $2.4424 E-01$ \\
2.0 & $4.8047 E-02$ & $2.4753 E-02$ \\
4.0 & $3.5515 E-02$ & $5.6572 E-05$ \\
5.0 & $2.7221 E-02$ & $4.6744 E-07$ \\
6.0 & $2.5790 E-02$ & $1.6468 E-10$ \\
8.0 & $2.0809 E-02$ & $1.3385 E-11$ \\
10.0 & $1.7408 E-02$ & $4.0019 E-15$ \\
14.0 & $1.6381 E-02$ & $2.1848 E-18$ \\
16.0 & $4.4111 E-19$ \\
\hline & \\
&
\end{tabular}

Substituting (29) into (28), the expression can be rewritten as follows:

$$
f(p, q)=-q+M_{0} p+c_{0}\left[1-\left(\frac{p}{C_{1}}\right)^{t}\right] \exp \left[\left(\frac{p}{C_{1}}\right)^{t}\right],
$$

where $q$ is the deviatoric stress, $p$ is the mean stress, and $c_{0}$ is the intercept of the strength curve in the meridian 


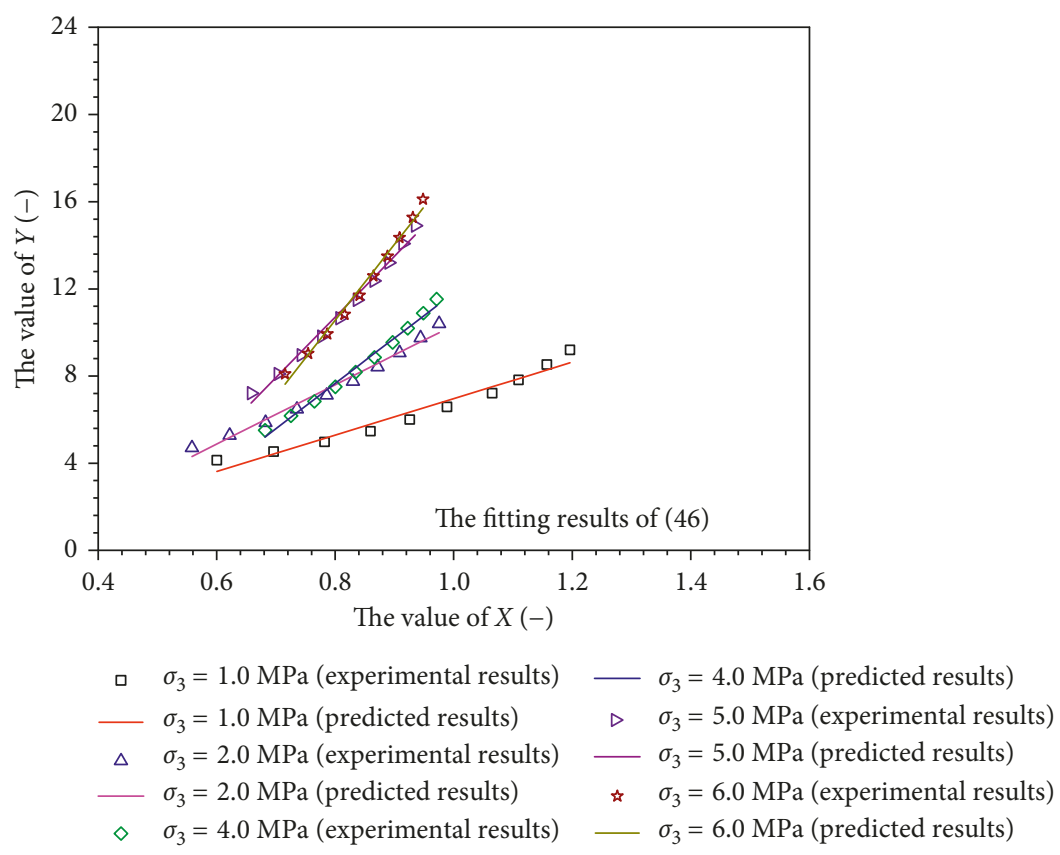

(a)

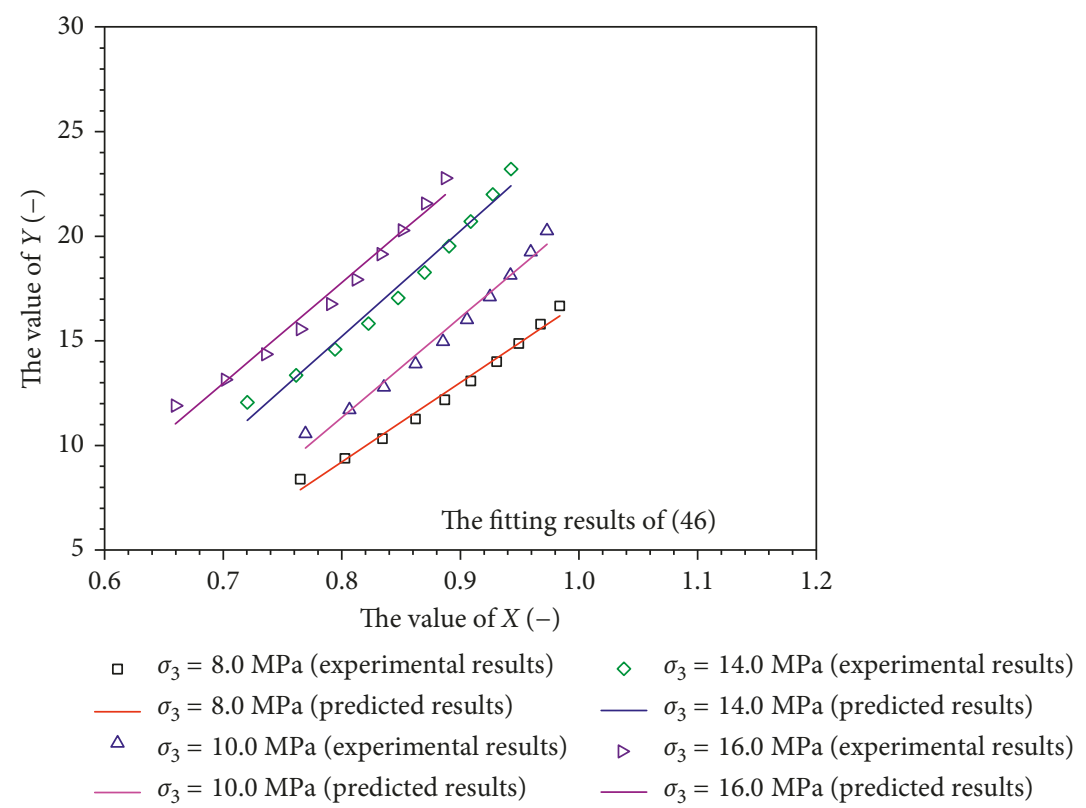

(b)

Figure 11: The relationship between the parameters $Y$ and $X$ of (46) under different confining pressures: (a) 1.0-6.0 MPa and (b) $8.0-16.0 \mathrm{MPa}$.

plane. $M_{0}$ is the initial failure stress ratio, equal to the slope of the curve. The parameter $C_{1}$ is related to pressure melting, which reflects the changing rate about $q$ with the increase of hydrostatic pressure, and $t$ denotes the material parameter.

As is depicted in Figure 8, when the mean stress $p$ is lower than $p_{\mathrm{cr}}$, the modified failure state line can describe the strengthened effect; when the mean stress $p$ is higher than $p_{\mathrm{cr}}$, it denotes the weakened effect for frozen sandy soils.
The mean stress $p$ and the deviatoric stress $q$ can be written in the following form:

$$
\begin{aligned}
& p=\frac{\sigma_{1}+\sigma_{2}+\sigma_{3}}{3}=\frac{1}{3} \sigma_{i i}, \\
& q=\sqrt{3 J_{2}}=\sqrt{\frac{3}{2} s_{i j} s_{i j}},
\end{aligned}
$$




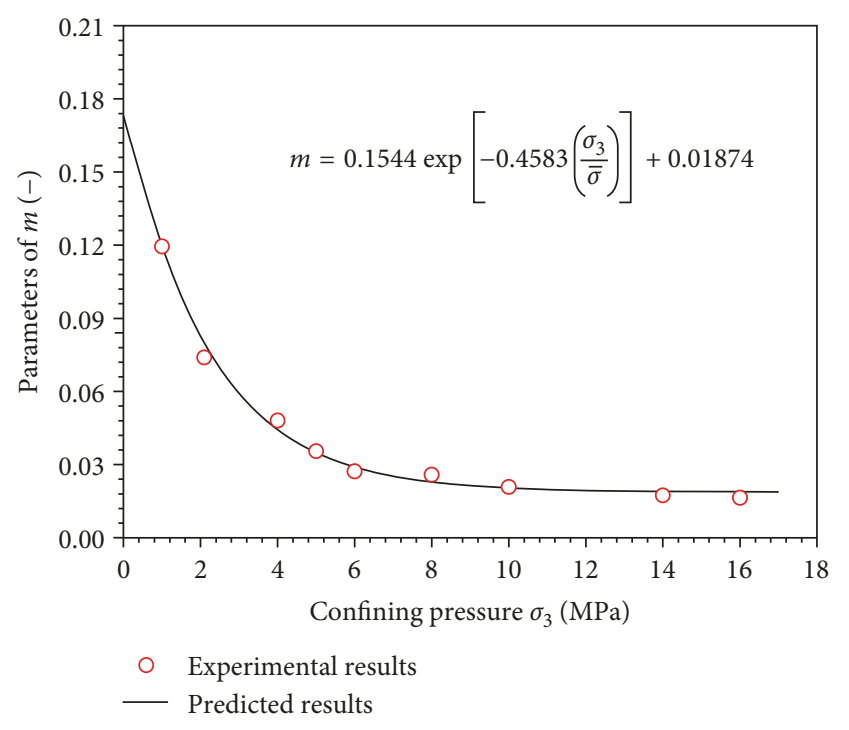

FIGURE 12: The relationship between the parameter $m$ and confining pressures.

$$
s_{i j}=\sigma_{i j}-\frac{1}{3} \delta_{i j} \sigma_{k k}
$$

where $\sigma_{1}, \sigma_{2}$, and $\sigma_{3}$ are the first, second, and third principal stresses, respectively; $J_{2}$ is the second deviatoric stress variant; $\sigma_{i j}$ is the stress tensor; $s_{i j}$ is the deviatoric stress tensor; and $\delta_{i j}$ is the Kronecker function.

Based upon the assumptions, it is easily accepted that the microstrength of frozen soils satisfies the modified failure state line; so, the strength criterion expression of the effective stress can be obtained as follows:

$$
\begin{aligned}
F\left(p^{*}, q^{*}\right) & =f\left(p^{*}, q^{*}\right) \\
& =-q^{*}+M_{0} p^{*}+c_{0}\left[1-\left(\frac{p^{*}}{C_{1}}\right)^{t}\right] \exp \left[\left(\frac{p^{*}}{C_{1}}\right)^{t}\right],
\end{aligned}
$$

where $p^{*}$ and $q^{*}$ denote the effective mean stress and deviatoric stress, respectively.

According to (22), the effective stress and apparent stress can be rewritten as follows:

$$
\begin{gathered}
\sigma_{i j}=\left(I_{i j k l}-D_{i j k l}\right) \sigma_{k l}^{*}, \\
\sigma_{i j}^{*}=\lambda \delta_{i j} \varepsilon_{k k}+2 G \varepsilon_{i j} .
\end{gathered}
$$

Substituting (27) and (36) into (35), the stress expression can be rewritten as

$$
\sigma_{i j}=\left(\lambda \delta_{i j} \varepsilon_{k k}+2 G \varepsilon_{i j}\right) \exp \left[-\left(\frac{F}{F_{0}}\right)^{m}\right] .
$$

The elastic constants $\lambda$ and $G$ can be obtained as follows:

$$
\begin{aligned}
& \lambda=\frac{E \mu}{(1+\mu)(1-2 \mu)}=K-\frac{2}{3} G, \\
& G=\frac{E}{2(1+\mu)},
\end{aligned}
$$

where $\lambda$ denotes the Lame constant and $K$ and $G$ are the bulk modulus and shear modulus, respectively.

Based upon the generalized Hooke's law, the expression of axial strain $\varepsilon_{1}$ can be expressed by

$$
\varepsilon_{1}=\frac{1}{1-D} \cdot \frac{\sigma_{1}-\mu\left(\sigma_{2}+\sigma_{3}\right)}{E} .
$$

Hence, the effective mean stress and deviatoric stress can be obtained as follows:

$$
\begin{aligned}
& p^{*}=\frac{p}{1-D}=\frac{E \varepsilon_{1} p}{\sigma_{1}-\mu\left(\sigma_{2}+\sigma_{3}\right)} \\
& q^{*}=\frac{q}{1-D}=\frac{E \varepsilon_{1} q}{\sigma_{1}-\mu\left(\sigma_{2}+\sigma_{3}\right)} .
\end{aligned}
$$

Substituting (38) to (42) into (37), the formula can be obtained by a series of mathematical calculation and transformation

$$
\ln \left\{-\ln \left[\frac{\sigma_{i j}}{\lambda \delta_{i j} \varepsilon_{k k}+2 G \varepsilon_{i j}}\right]\right\}=m \ln F-m \ln F_{0} .
$$

In order to obtain the material parameters, (43) can be converted to the following form:

$$
\begin{aligned}
X & =\ln \left\{-\ln \left[\frac{\sigma_{i j}}{\lambda \delta_{i j} \varepsilon_{k k}+2 G \varepsilon_{i j}}\right]\right\}, \\
Y & =\ln F\left(p^{*}, q^{*}\right) \\
& =\ln \left\{-q^{*}+M_{0} p^{*}+c_{0}\left[1-\left(\frac{p^{*}}{C_{1}}\right)^{t}\right] \exp \left[\left(\frac{p^{*}}{C_{1}}\right)^{t}\right]\right\} .
\end{aligned}
$$

Combining (44) with (45), we can get

$$
Y=\frac{1}{m} X+\ln F_{0} \text {. }
$$

Based upon triaxial compression test data from Figure 1, (46) can be used to obtain the parameters $m$ and $F_{0}$.

\subsection{Parameter Determination}

4.4.1. Determination of Bulk Modulus K and Shear Modulus G. Based upon test data from Figure 1, the basic physical parameters can be determined, such as the bulk modulus $K$ and shear modulus $G$, in the initial elastic stage, as shown in Table 1.

In order to describe the changing evolution of the bulk modulus $K$ and shear modulus $G$, the mathematical relationship can be expressed by

$$
\begin{aligned}
& K=K_{p} P_{a}\left[a_{p}+\left(\frac{\sigma_{3}}{P_{a}}\right)^{n_{p}}\right], \\
& G=P_{a}\left[a_{g}\left(\frac{\sigma_{3}}{P_{a}}\right)^{2}+b_{g} \frac{\sigma_{3}}{P_{a}}+c_{g}\right],
\end{aligned}
$$




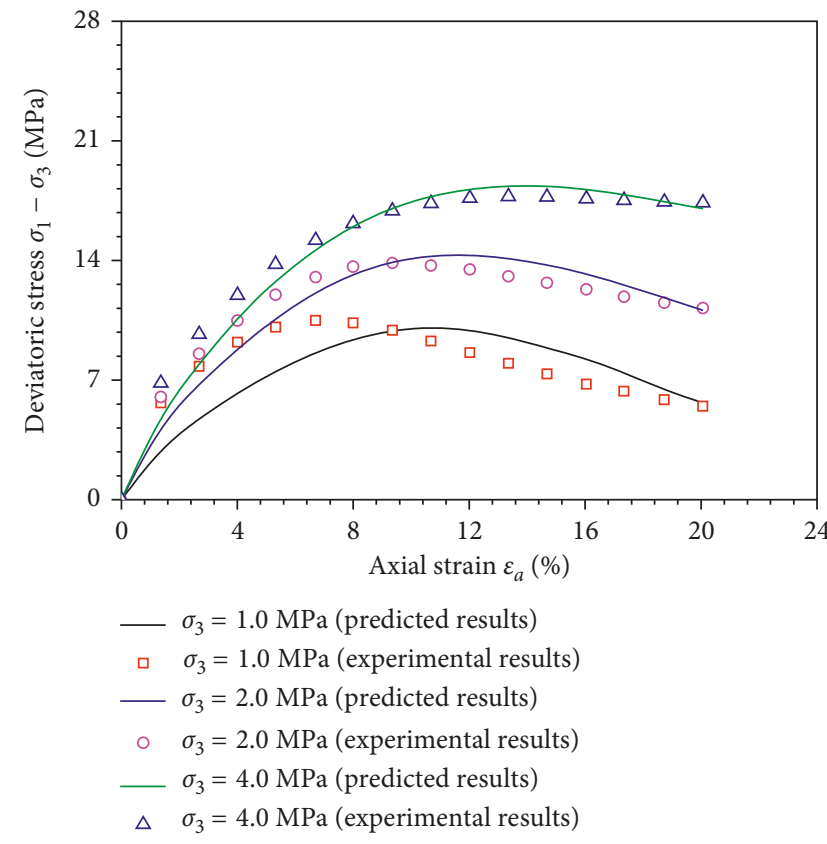

(a)

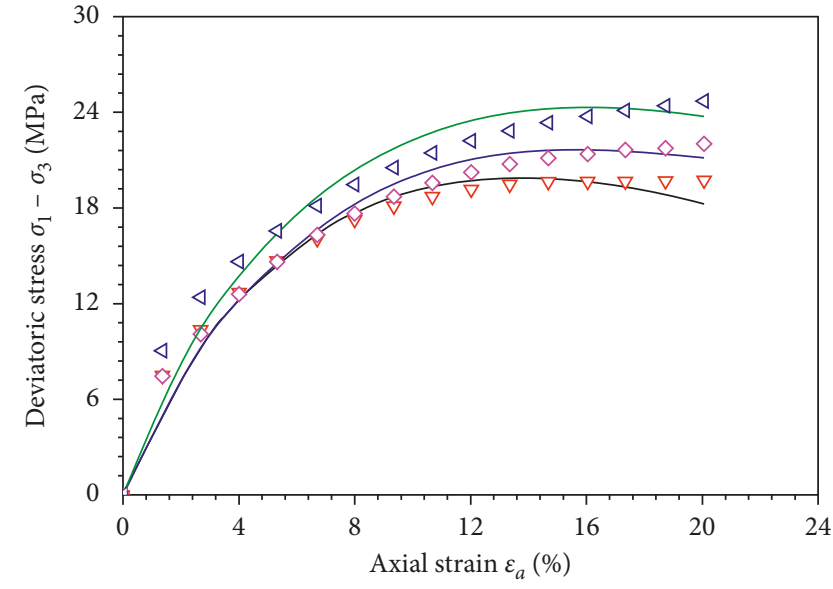

$-\sigma_{3}=5.0 \mathrm{MPa}$ (predicted results)

$\nabla \sigma_{3}=5.0 \mathrm{MPa}$ (experimental results)

- $\sigma_{3}=6.0 \mathrm{MPa}$ (predicted results)

$\diamond \sigma_{3}=6.0 \mathrm{MPa}$ (experimental results)

$-\sigma_{3}=8.0 \mathrm{MPa}$ (predicted results)

$\triangleleft \sigma_{3}=8.0 \mathrm{MPa}$ (experimental results)

(b)

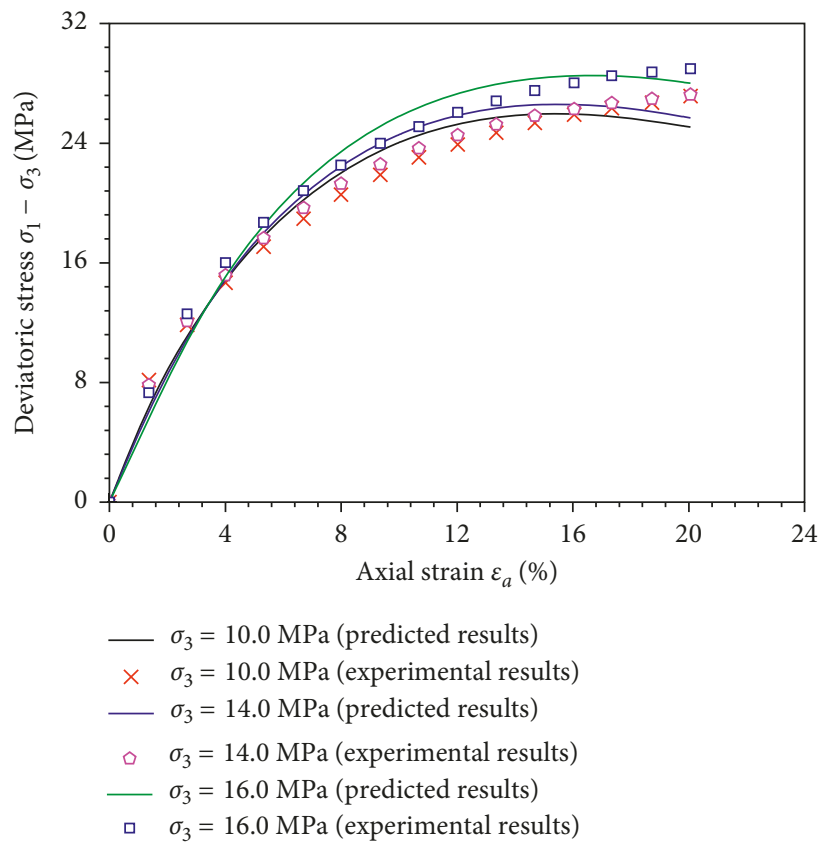

(c)

Figure 13: Comparisons between test data and predicted results of deviatoric stress-axial strain under different confining pressures: (a) 1.0-4.0 MPa, (b) 5.0-8.0 MPa, and (c) 10.0-16.0 MPa.

where $P_{a}$ is the atmospheric pressure $\left(P_{a}=0.10133 \mathrm{MPa}\right)$ and $K_{p}, a_{p}, n_{p}$ and $a_{g}, b_{g}, c_{g}$ are material parameters. In this paper, the fitting results are illustrated in Figure 9: $K_{p}=13350, a_{p}=-2.05, n_{p}=0.3637$ and $a_{g}=-0.3757$, $b_{g}=85.86, c_{g}=3534$.

4.4.2. Parameter Determination of the Strength Criterion. According to the cryogenic triaxial compression test data as is illustrated in Figure 1, the values of fitting parameters are shown in Table 2 and the corresponding fitting curve in Figure 10. It can be found that the proposed criterion has a good application for frozen sandy soils, especially the correlation coefficient $R^{2}$ reaching the value of 0.9971 .

4.4.3. Parameter Determination of the Damage Statistical Constitutive Model. The values of fitting parameters of (46) can be obtained from triaxial compression test data. Hence, $m$ 
TABle 4: Parameter determination of (55).

\begin{tabular}{lcr}
\hline $\begin{array}{l}\text { Confining pressures, } \\
\sigma_{3}(\mathrm{MPa})\end{array}$ & $m_{d}$ & Parameter determination \\
\hline 1.0 & -105.1 & $n_{d}$ \\
2.0 & 0.0822 & 0.4253 \\
4.0 & 0.5258 & 0.8487 \\
5.0 & 0.4875 & 0.5862 \\
6.0 & 0.5064 & 0.7570 \\
8.0 & 0.5189 & 0.7930 \\
10.0 & 0.5487 & 0.8119 \\
14.0 & 0.5201 & 0.8896 \\
16.0 & 0.4083 & 0.9199 \\
\hline
\end{tabular}

and $F_{0}$ can be found in Table 3. The fitting results of (46) are depicted in Figure 11. It can be found that the relationship between $Y$ and $X$ presents a good linear relationship.

As presented in Figure 12, the relationship between the parameter $m$ and confining pressures can be expressed as follows:

$$
m=0.1544 \exp \left[-0.4583\left(\frac{\sigma_{3}}{\bar{\sigma}}\right)\right]+0.01874,
$$

where $\bar{\sigma}$ means 1.0 MPa to keep the $\sigma_{3} / \bar{\sigma}$ dimensionless.

\subsection{Verification}

4.5.1. Verification of Deviatoric Stress-Axial Strain. After determining the model parameters, the stress under different confining pressures can be calculated by (37). Comparisons of the curves between experimental data and predicted results are depicted in Figure 13. It can be found that this proposed statistical damage constitutive model can simulate the softening phenomenon under low confining pressures and hardening phenomenon under high confining pressures. As a whole, the proposed model has a relatively high accuracy, so it is quite convenient for practical engineering.

4.5.2. Verification of Volumetric Strain-Axial Strain. In order to simulate the volumetric strain of frozen sandy soils, we give a damage relationship from the mesolevel, and the expression is shown as follows:

$$
\varepsilon_{i j}=\frac{V^{\text {initial }}}{V} \varepsilon_{i j}^{\text {initial }}+\frac{V^{\text {damage }}}{V} \varepsilon_{i j}^{\text {damage }},
$$

where $V^{\text {initial }}$ denotes the initial volume of the specimen, $V^{\text {damage }}$ denotes the damage volume of the specimen, and $V$ denotes the total volume of the specimen.

From (30), we know the invariant relationship of $V=V^{\text {initial }}+V^{\text {damage }}$; hence, $(50)$ can be rewritten as

$$
\varepsilon_{i j}=\left(1-\frac{V^{\text {damage }}}{V}\right) \varepsilon_{i j}^{\text {initial }}+\frac{V^{\text {damage }}}{V} \varepsilon_{i j}^{\text {damage }} .
$$

Based on the theory framework of continuum damage mechanics (CDM), the damage variable can also be redefined as

$$
D=\frac{V^{\text {damage }}}{V} .
$$

So, the strain tensor of (51) can be rewritten as follows:

$$
\varepsilon_{i j}=\left(I_{i j k l}-D_{i j k l}\right) \varepsilon_{k l}^{\text {initial }}+D_{i j k l} \varepsilon_{k l}^{\text {damage }}
$$

Under the triaxial symmetric compression condition, the volumetric strain of (53) can be expressed as

$$
\varepsilon_{v}=(1-D) \varepsilon_{v}^{\text {initial }}+D \varepsilon_{v}^{\text {damage }} .
$$

We make an assumption of $\varepsilon_{v}^{\text {initial }}=p / K$ for the initial elastic part and $\varepsilon_{v}^{\text {damage }}=m_{d} \varepsilon_{1}^{n_{d}}$ for the damage part; hence, the following expression can be obtained:

$$
\varepsilon_{v}=\exp \left[-\left(\frac{F}{F_{0}}\right)^{m}\right] \frac{p}{K}+\left\{1-\exp \left[-\left(\frac{F}{F_{0}}\right)^{m}\right]\right\} m_{d} \varepsilon_{1}^{n_{d}},
$$

where $m_{d}$ and $n_{d}$ are the material parameters, which can be determined by experimental data.

From Tables 3 and 4, the curves of volumetric strainaxial strain can be obtained as are illustrated in Figure 14. It can be found from Figure 14 that (55) can well simulate the experimental data, which present firstly compression and then dilation phenomenon under relatively low confining pressures and merely compression under high confining pressures.

\section{Conclusions}

In this paper, a new nonlinear strength criterion is proposed, and a damage statistical constitutive model is also established. The following conclusions can be reached:

(1) The relationship between $\sigma_{1}$ and $\sigma_{3}$ is proposed based upon experimental results of frozen sandy soils. It is illustrated that the proposed equation is more close to experimental results than the classical strength criteria, such as Mohr-Coulomb and Hoek-Brown strength criteria. And then, the equation is introduced into the $\sigma$ - $\tau$ plane to investigate the nonlinear strength properties based on failure envelope theorem. Compared with test data, the predicted results have a good accuracy and appropriateness. 


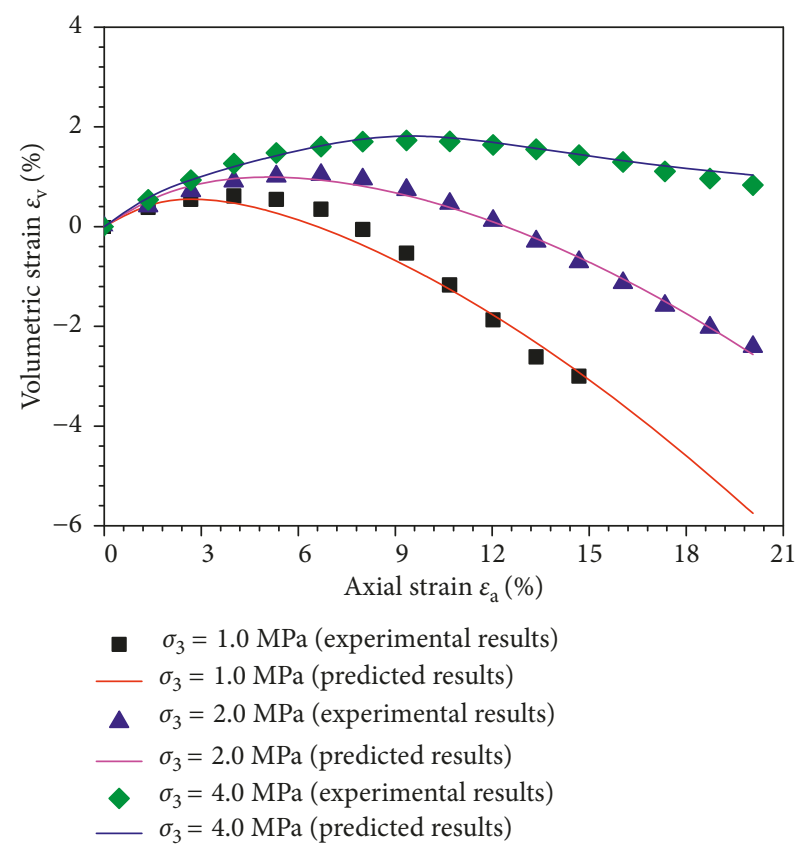

(a)

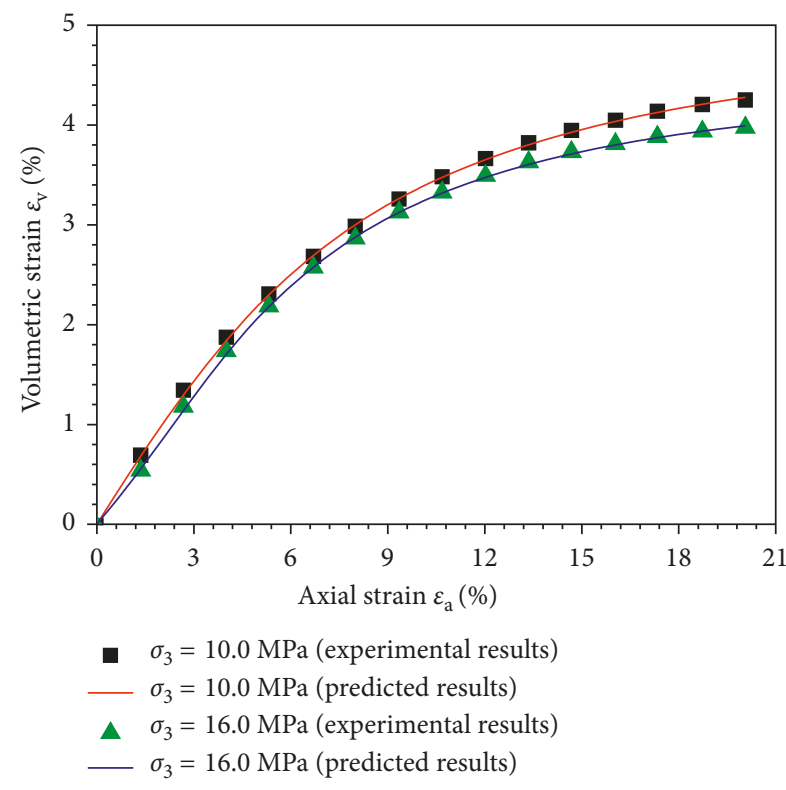

(c)

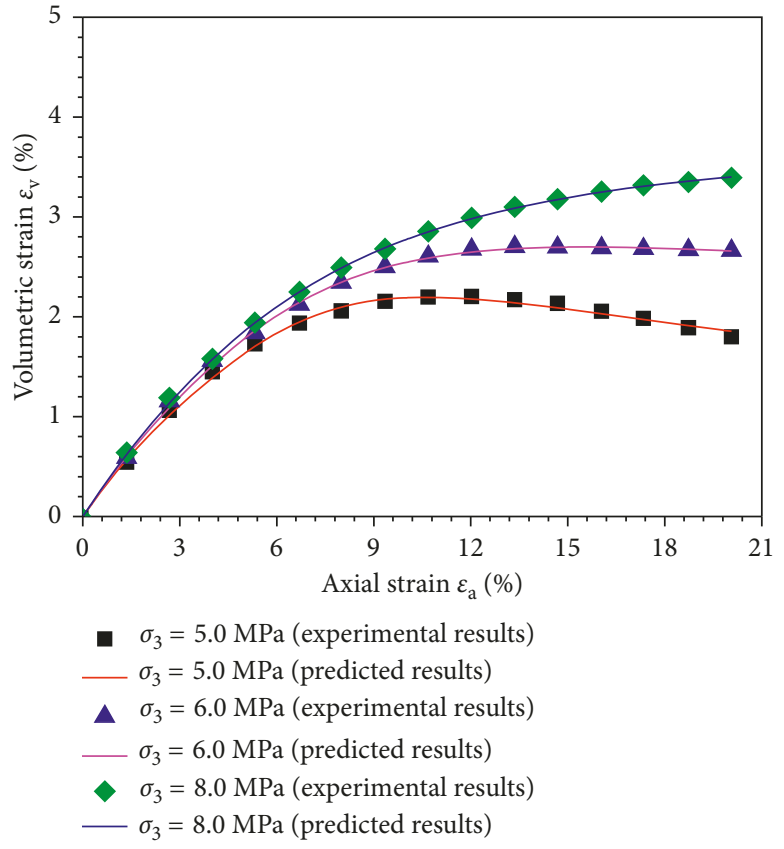

(b)

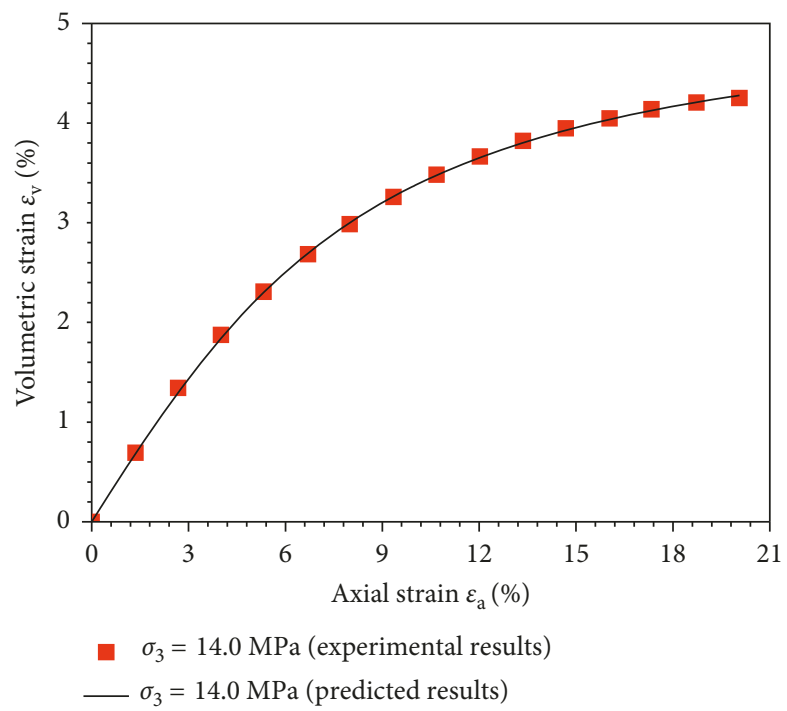

(d)

FIGURE 14: Comparisons between test data and predicted results of volumetric strain-axial strain under different confining pressures: (a) 1.0-4.0 MPa, (b) 5.0-8.0 MPa, (c) 10.0 and 16.0 MPa, and (d) $14.0 \mathrm{MPa}$.

(2) The microstrength of frozen sandy soils obeys the Weibull distribution function. The strength criterion, which contains the damage properties of microstrength, is chosen as an independent variable in damage variable $D$. The parameters related to the damage statistical constitutive model are determined by experimental data, and they can well simulate both the curves of deviatoric stress-axial strain and volumetric strain-axial strain.

\section{Additional Points}

Highlights. (1) A new strength criterion is proposed based on experimental results, and the nonlinear strength properties are considered. (2) The stress and volumetric strain-axial strain at different confining pressures are validated by damage statistical constitutive model. (3) The damage constitutive model can simulate the strain softening and hardening phenomenon for frozen sandy soils. 


\section{Conflicts of Interest}

The authors declare that there are no conflicts of interest.

\section{Acknowledgments}

The authors appreciate the funding provided by the CAS Pioneer Hundred Talents Program (Dr. Liu Enlong) and National Science Foundation of China (41771066).

\section{References}

[1] X. Z. Xu, J. C. Wang, and L. X. Zhang, Physics of Frozen Soils, Science press in Chinese, Beijing, China, 2009.

[2] H. M. French, The Periglacial Environment, Essex, London, UK, 2nd edition, 1996.

[3] N. A. Tsytovich, The Mechanics of Frozen Ground, Science Press, Beijing, China, 1985.

[4] H. Matsuoka and T. Nakai, "Stress-deformation and strength characteristics of soil under three different principal stresses," Japan Society of Civil Engineers, vol. 1974, no. 232, pp. 59-70, 1974.

[5] M. D. Liu and J. P. Carter, "General strength criterion for geomaterials," International Journal of Geomechanics, vol. 3, no. 2, pp. 253-259, 2003.

[6] M. D. Liu and B. N. Indraratna, "General strength criterion for geomaterials including anisotropic effect," International Journal of Geomechanics, vol. 11, no. 3, pp. 251-262, 2010.

[7] M. C. Liu, Y. F. Gao, and H. L. Liu, "A nonlinear DruckerPrager and Matsuoka-Nakai unified failure criterion for geomaterials with separated stress invariants," International Journal of Rock Mechanics and Mining Sciences, vol. 50, pp. 1-10, 2012.

[8] Y. P. Yao and D. A. Sun, "Application of Lade's criterion to Cam-clay model," Journal of Engineering Mechanics, vol. 126, no. 1, pp. 112-119, 2000.

[9] Y. P. Yao and A. N. Zhou, "Non-isothermal unified hardening model: a thermo-elasto-plastic model for clays," Geotechnique, vol. 63, no. 15, pp. 1328-1345, 2013.

[10] Y. P. Yao, D. A. Sun, and T. Luo, "A critical state model for sands dependent on stress and density," International Journal for Numerical and Analytical Methods in Geomechanics, vol. 28, no. 4, pp. 323-337, 2004.

[11] Y. P. Yao, W. Hou, and A. N. Zhou, "UH model: threedimensional unified hardening model for overconsolidated clays," Geotechnique, vol. 59, no. 5, pp. 451-469, 2009.

[12] E. L. Liu, Q. Nie, and J. H. Zhang, "A new strength criterion for structured soils," Journal of Rock Mechanics and Geotechnical Engineering, vol. 5, pp. 156-161, 2013.

[13] A. M. Fish, "Strength of frozen soil under a combined stress state," Sixth International Symposium on Ground Freezing, vol. 1, pp. 135-145, 1991.

[14] W. Ma, Z. W. Wu, and Y. Sheng, "Effect of confining pressure on strength behaviour of frozen soil," Chinese Journal Geotechnical Engineering, vol. 17, no. 5, pp. 7-11, 1995.

[15] J. L. Qi and W. Ma, "A new criterion for strength of frozen sand under quick triaxial compression considering effect of cofining pressure," Acta Geotechnica, vol. 2, pp. 221-226, 2007.

[16] Y. M. Lai, Y. G. Yang, X. X. Chang, and S. Y. Li, "Strength criterion and elastoplastic constitutive model of frozen silt in generalized plastic-mechanics," International Journal of Plasticity, vol. 26, no. 10, pp. 1461-1484, 2010.

[17] Y. M. Lai, M. K. Liao, and K. Hu, "A constitutive model of frozen saline sandy soil based on energy dissipation theory,"
International Journal of Plasticity, vol. 78, no. 3, pp. 84-113, 2016.

[18] M. K. Liao, Y. M. Lai, and C. Wang, "A strength criterion for frozen sodium sulfate saline soil," Canadian Geotechnical Journal, vol. 53, no. 7, pp. 1176-1185, 2016.

[19] Y. M. Lai, Z. H. Gao, and S. J. Zhang, "Stress-strain relationships and nonlinear Mohr strength criteria of frozen sandy clay," Soils and Foundations, vol. 50, no. 1, pp. 45-53, 2010.

[20] W. G. Cao, Z. L. Fang, and X. J. Tang, "A study of statistical constitutive model for softening and damage rocks," Chinese Journal of Rock Mechanics and Engineering, vol. 17, no. 6, pp. 628-633, 1998.

[21] W. G. Cao, M. H. Zhao, and C. X. Liu, "A study on damage statistical strength theory for rock," Chinese Journal of Geotechnical Engineering, vol. 26, no. 6, pp. 820-823, 2004.

[22] W. G. Cao, P. Li, and M. H. Zhao, "On statistical damage constitutive model and its parameters for rock based on normal distribution," Chinese Hydrogeology \& Engineering Geology, vol. 32, no. 3, pp. 11-14, 2008.

[23] J. Deng and D. Gu, "On a statistical damage constitutive model for rock materials," Computers \& Geosciences, vol. 37, no. 2, pp. 122-128, 2011.

[24] X. Li, W. G. Cao, and Y. H. Su, "A statistical damage constitutive model for softening behavior of rocks," Engineering Geology, vol. 143, pp. 1-17, 2012.

[25] H. Li, H. Liao, and G. Xiong, "A three-dimensional statistical damage constitutive model for geomaterials," Journal of Mechanical Science and Technology, vol. 29, no. 1, pp. 71-77, 2015.

[26] Z. L. Wang, Y. C. Li, and J. G. Wang, “A damage-softening statistical constitutive model considering rock residual strength," Computers \& Geosciences, vol. 33, no. 1, pp. 1-9, 2007.

[27] H. Xie and F. Gao, "The mechanics of cracks and a statistical strength theory for rocks," International Journal of Rock Mechanics \& Mining Sciences, vol. 37, no. 3, pp. 477-488, 2000.

[28] W. Y. Xu and L. D. Wei, "Study on statistical damage constitutive model of rock," Chinese Journal of Rock Mechanics and Engineering, vol. 21, no. 6, pp. 787-791, 2002.

[29] A. Shojaei, A. D. Taleghani, and G. Li, "A continuum damage failure model for hydraulic fracturing of porous rocks," International Journal of Plasticity, vol. 59, pp. 199-212, 2014.

[30] J. X. Ren and X. R. Ge, "Study of rock meso-damage evolution law and its constitutive model under uniaxial compression loading," Chinese Journal of Rock Mechanics and Engineering, vol. 20, no. 4, pp. 425-431, 2001.

[31] S. J. Zhang, Y. M. Lai, and X. M. Su, "A laboratory study on the damage propagation of rocks under freeze-thaw cycle condition," Chinese Journal of Rock Mechanics and Engineering, vol. 23, no. 24, pp. 4105-4111, 2004.

[32] J. X. Ren, "Real-time CT test of damage failure mechanism of frozen cracked rock in loading and unloading condition," Chinese Journal of Geotechnical Engineering, vol. 26, no. 5, pp. 641-644, 2004.

[33] Y. M. Lai, S. Y. Li, J. L. Qi, Z. H. Gao, and X. X. Chang, "Strength distributions of warm frozen clay and its stochastic damage constitutive model," Cold Regions Science and Technology, vol. 53, pp. 200-215, 2008.

[34] S. Y. Li, Y. M. Lai, S. J. Zhang, and D. Liu, “An improved statistical damage constitutive model for warm frozen clay based on Mohr-Coulomb criterion," Cold Regions Science and Technology, vol. 57, no. 2-3, pp. 154-159, 2009. 
[35] X. T. Xu, Y. M. Lai, Y. H. Dong, and J. L. Qi, "Laboratory investigation on strength and deformation characteristics of ice-saturated frozen sandy soil," Cold Regions Science and Technology, vol. 68, no. 1, pp. 98-104, 2011.

[36] E. Hoek, "The Hoek-Brown failure criterion," in Proceedings of 15th Canadian Rock Mechanics Symposium, pp. 31-38, Department of Civil Engineering, University of Toronto, Toronto, Canada, 1988.

[37] W. Ma, Z. W. Wu, L. X. Zhang, and X. Chang, "Analyses of process on the strength decrease in frozen soils under high confining pressures," Cold Regions Science and Technology, vol. 29, no. 1, pp. 1-7, 1999.

[38] J. A. Lemaitre, "How to use damage mechanics," Nuclear Engineering and Design, vol. 80, no. 2, pp. 233-245, 1984.

[39] Y. M. Lai, J. B. Li, and Q. Z. Li, "Study on damage statistical constitutive model and stochastic simulation for warm icerich frozen silt," Cold Regions Science and Technology, vol. 71, no. 2, pp. 102-110, 2012.

[40] W. Weibull, "A statistical distribution function of wide applicability," Journal of Applied Mechanics, vol. 18, pp. 293-297, 1951.

[41] K. H. Roscoe and J. B. Burland, "On the generalized stressstrain behaviour of wet clay," Engineering Plasticity, Cambridge University Press, Cambridge, UK, 1968.

[42] L. D. Nguyen, B. Fatahi, and H. Khabbaz, "A constitutive model for cemented clays capturing cementation degradation," International Journal of Plasticity, vol. 56, pp. 1-18, 2014. 


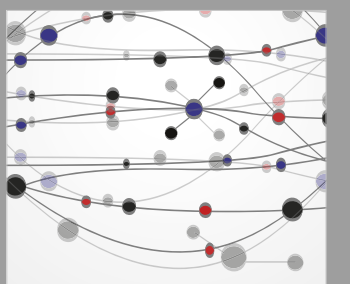

The Scientific World Journal
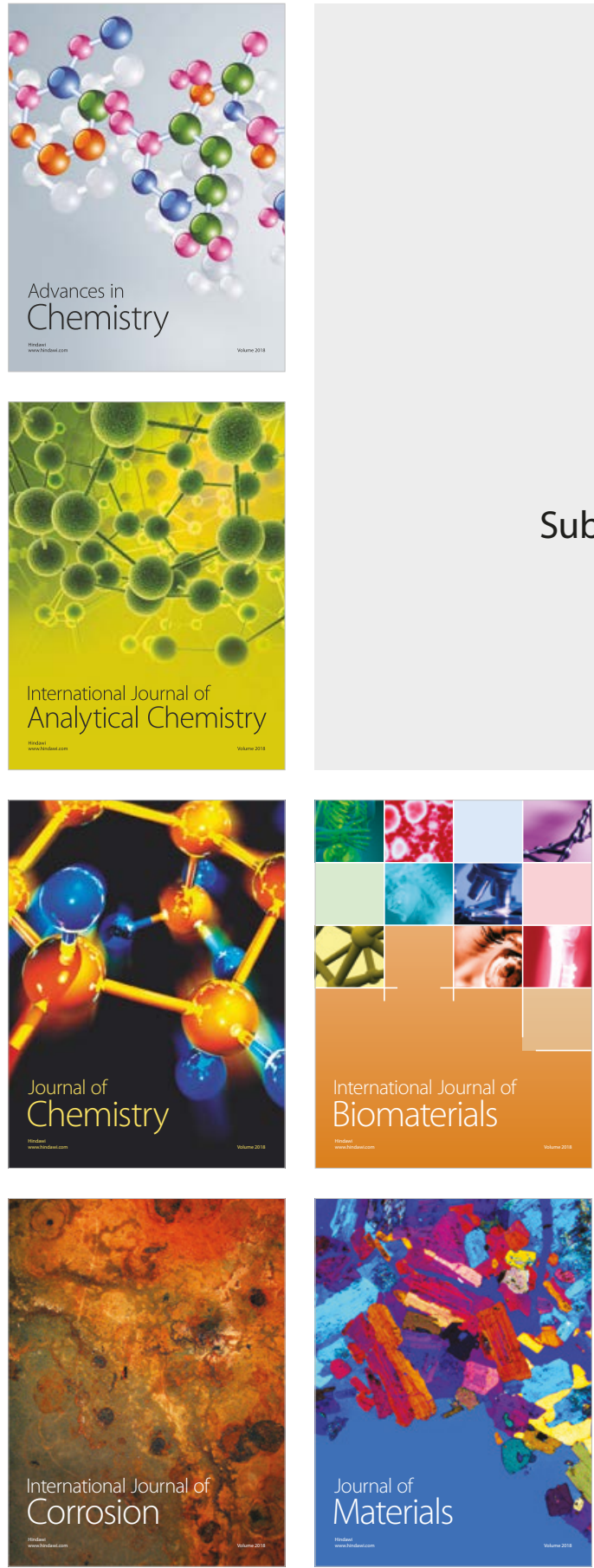

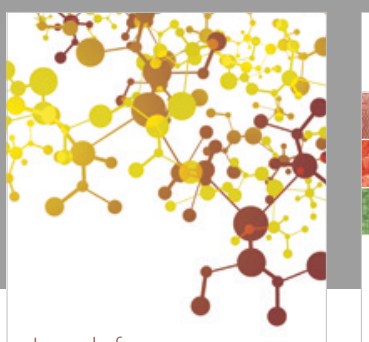

Journal of

Applied Chemistry
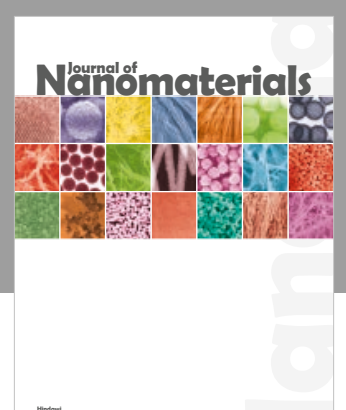

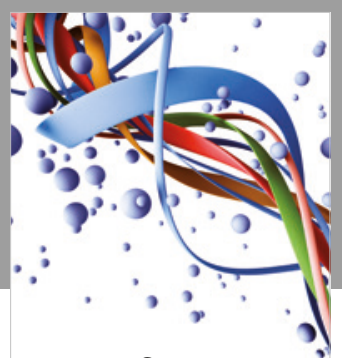

Scientifica

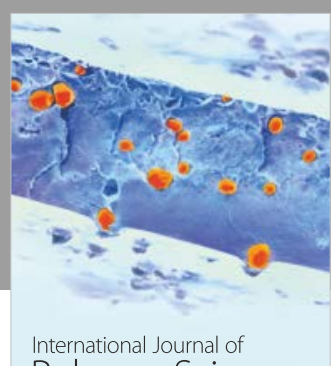

Polymer Science

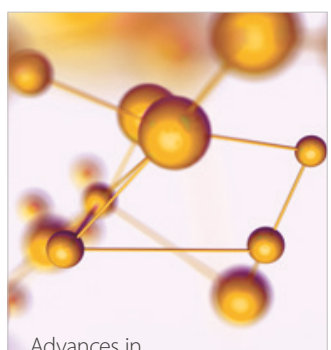

Physical Chemistry
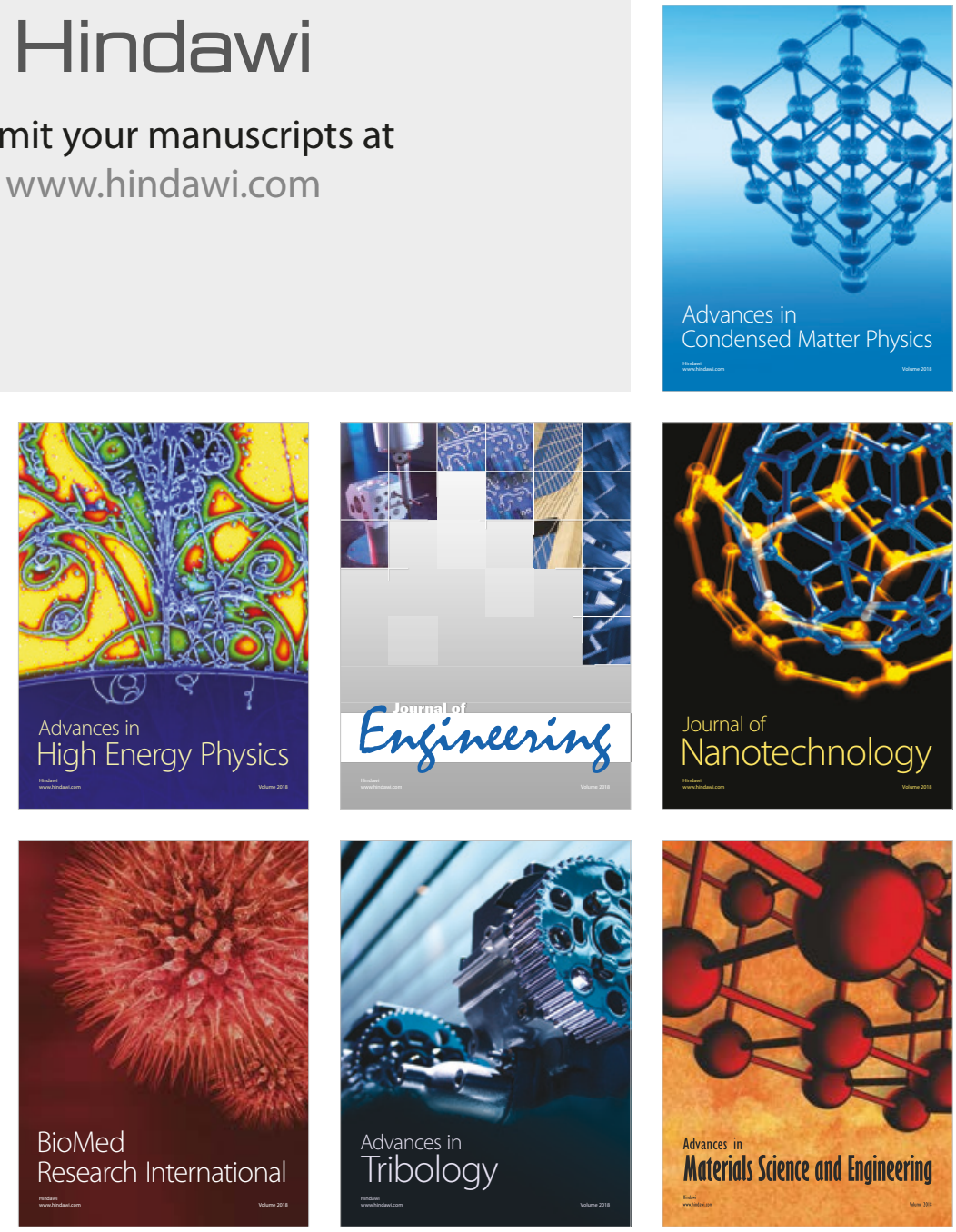